\title{
Coal Technology Program Quarterly Progress Report for the Period Ending December 31, 1975
}

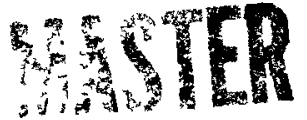

\section{OAK RIDGE NATIONAL LABORATORY}




\section{DISCLAIMER}

Portions of this document may be illegible in electronic image products. Images are produced from the best available original document. 
Printed in the United States of America. Avaliable from National Technical Information Service

U S. Department of Commerce 5285 Port Royal Road, Sprıngfield, Virgınıa 22161

Price Prınted Copy $\$ 5.00$, Mıcrofıche $\$ 2.25$

This report was prepared as an account of work sponsored by the United States Government Neither the United States nor the Energy Research and Development Administration, nor any of their employees, nor any of their contractors, subcontractors, or their employees, makes any warranty, express or implied, or assumes any legal liabılity or responsibılity for the accuracy, completeness or usefulness of any information, apparatus, product or process disclosed, or represents that its use would not infringe privately owned rights 


\section{ORNL-5I20 \\ UC-90d - Coal Conversion and \\ Utilization - Liquefaction}

Contract No. W-7405-eng-26

COAL TECHNOLOGY PROGRAM

QUARTERLY PROGRESS REPORT FOR THE

PERIOD ENDING DECEMBER 31, 1975

\section{MARCH 1976}

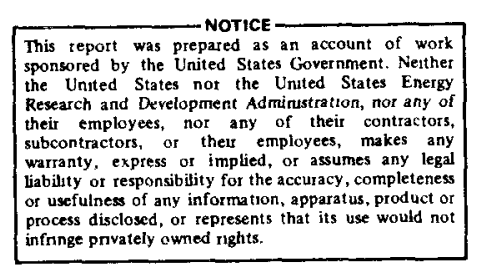

OAK RIDGE NATIONAL LABORATORY

Oak Ridge, Tennessee 37830

operated by

UNION CARBIDE CORPORATION

for the

ENERGY RESEARCH AND DEVELOPMENT ADMINISTRATION 
REPORTS PREVIOUSLY ISSUED IN THIS SERIES

ORNL-5026, Coal Technology Program Quarterly Progress Report for the Period Ending December 31, 1974

ORNL-5049, Coal Technology Program Quarterly Progress Report for the Period Ending March 31, 1975

ORNL-5069, Coal Technology Program Annual Interim Report for Fiscal Year Ending June 30, 1975

ORNL-5093, Coal Technology Program Quarterly Progress Report for the Period Ending September 30, 1975 
Abstract ......................... 1

1. Summary . . . . . . . . . . . . . . . . . . I

2. Hydrocarbonization Research . . . . . . . . . . . 3

2.1 Experimental Development . . . . . . . . . . . 3

2.2 Bench-Scale System . . . . . . . . . . . 8

2.3 Residua Carbonization . . . . . . . . . . . . 14

2.4 References for sect. 2 .............. 16

3. Supporting Research and Development in

Separations Technology . . . . . . . . . . . . . . 21

3.1 Batch Settling Studies . . . . . . . . . . . . 22

3.2 Semicontinuous Settling Studies . . . . . . . . . 26

3.3 Additive Agglomeration Studies . . . . . . . . . . 26

3.4 Bench-Scale Development . . . . . . . . . . . . 29

3.5 Characterization Studies . . . . . . . . . . 30

3.6 References for sect. 3 . . . . . . . . . . . 39

4. Chemical Research and Development . . . . . . . . . . 42

4.1 Physical Structure of Coal . . . . . . . . . . 42

4.2 Properties of Catalyst Surfaces . . . . . . . . . . 43

4.3 Chemistry of Heteroatom Removal from Coal . . . . . . . 46

5. Analytical Chemistry . . . . . . . . . . . . . 50

5.1 Analytical Research and Development . . . . . . . . 50

5.2 Analytical Services . . . . . . . . . . . . 52

6. Engineering Evaluations of the Hydrocarbonization

and Synthoil Processes . . . . . . . . . . . . 54

6.1 Synthoil Process . . . . . . . . . . . . . . 55

6.2 Hydrocarbonization Process ............ 60

7. Biomedical and Environmental Research . . . . . . . . . 64

7.1 Biology Division . . . . . . . . . . . . . 64

7.2 Environmental Sciences Division . . . . . . . . . 65

7.3 Information Division . . . . . . . . . . . . 73

7.4 Health Physics Division.............. . 74

8. Engineering Evaluations of Nuclear Process

Heat for Coal Conversion . . . . . . . . . . . . . . 75 
COAL TECHNOLOGY PROGRAM QUARTERLY PROGRESS REPORT

FOR THE PERIOD ENDING DECEMBER 31, 1975

ABSTRACT

This report - the fifth of a series - is a compendium of quarterly progress reports for Oak Ridge National Laboratory research and development projects that are carried out in support of the increased utilization of coal as a source of clean energy. The progress reported for this period is for projects supported by the ERDA Divisions of Coal Conversion and Utilization, Fossil Demonstration Plants, Fossil Energy Research, Physical Research, and Biomedical and Environmental Research.

\section{SUMMARY}

J. P. Nichols

Highlights of progress through December 31, 1975, are summarized below:

- In the hydrocarbonization research program, installation of the bench-scale system was completed and initial pressurization took place in October followed by heat up, leak checking, and testing of instrumentation. During November, two shakedown runs were completed using 5 and $20 \mathrm{Ib}$ of pulverized coal as feed and pyrolyzing the coal at $\sim 1050^{\circ} \mathrm{F}$ under $5 \mathrm{~atm}$ of nitrogen pressure. In December, two runs were made using nitrogen as the feed gas at full system temperature and pressure.

- In the separations technology program, laboratory-scale tests continue to determine the optimum combination of solvent concentration and temperature on SRC and UFO. Continuous settling studies were initiated on a low priority basis to evaluate some parameters of a continuous flow system. Some excellent results have been obtained in the additive agglomeration studies using liquid additives designed for the petroleum industry. Also, characterization studies of SRC oils continue using a number of methods. 
- The chemical research and development effort continues with studies on several aspects of the physical structure of coal, the sorption and desorption of water vapor on a cobalt-molybdenum catalyst, and the catalytic chemistry of the same catalyst.

- In the aralytical chemistry work, Synthoil and COED process oil samples have been chemically fractionated for biological and chemical characterization. Development continues on achieving cleaner fractionation of chemical classes than has previously been afforded by more conventional schemes. Studies have begun to characterize aqueous effluents from the synthane process and in-situ shale oil retorting.

- In the engineering evaluations program, contacts continue to be made with industry to obtain information for the Synthoil process. Conceptual design of the solids-liquid separation plant was completed. A preliminary facility site plan was developed. For the hydrocarbonization process, the overall flow diagram and material balance were completed, based on estimated yields from U.S. Steel's "Clean Coke" process. This process will be recommended for evaluation as a scaled-down demonstration plant.

- Research activities continue in biomedical and environmental research. A feasibility study has shown the coupling of a lower tier testing system with chemical fractionation to be a valid system. Investigation into the fate and availability of a model PAH compound in water has begun. Acquisition of literature on the bioaccurnulation and toxicity of trace elements released in aqueous effluents of coal conversion has been completed.

- In the engineering evaluations of nuclear process heat for coal conversion, preliminary design of a plant for steam gasifying coal with VHTR heat has been completed.

- Our quarterly progress in the Coal-Fueled MIUS project is being published separately. The work included continued conceptual design studies of the fluidized bed and heat exchangers as well as the initiation of fabrication of several models that will be used for cold flow testing of the fluidized-bed concept. 


\section{HYDROCARBONIZATION RESEARCH}

H. D. Cochran, Jr.

$\underline{\text { Summary }}$

The revised milestone chart for this project is presented as Fig. 2.1. The review and evaluation of existing process technology (Task I) was completed on schedule, and a summary report was published. ${ }^{1}$

Effort during the past quarter was focused on completion and shakedown testing of the bench-scale system (Task 3). During October, installation was completed sufficiently to permit initial pressurization, heat up, leak checking, and testing of gas flow control and instruments. During November, the first two shakedown runs were completed successfully. In the first run, some $5 \mathrm{lb}$ of pulverized coal was fed to the reactor and pyrolyzed at $\sim 1050^{\circ} \mathrm{F}$ under $5 \mathrm{~atm}$ nitrogen pressure. In the second run, 20 Ib of pulverized coal was fed and pyrolyzed at similar conditions. During December, two runs were made with the bench-scale system using nitrogen as the feed gas at full system temperature and pressure.

\section{I Experimental Development}

J. B. Gibson, P. R. Westmoreland, and J. C. Rose

Ambient mock-ups

Effort on this task was curtailed during the quarter. No effort is planned in this area during the next quarter.

\section{High-temperature studies}

Analytical results from the first experiment with hydrogen as feed gas (run AHC-5) are now complete. Table 2.1 presents product gas analyses from run AHC-5. Table 2.2 presents proximate and ultimate analyses of feed coal, tar, and char from run AHC-5. Table 2.3 presents a carbon balance for run AHC-5. The material balance was closed within $2 \%$, but the relative yields of char, liquid, and gas indicate that at this operating temperature $\left(\sim 1100^{\circ} \mathrm{F}\right)$ considerable cracking of liquid products may have occurred. 


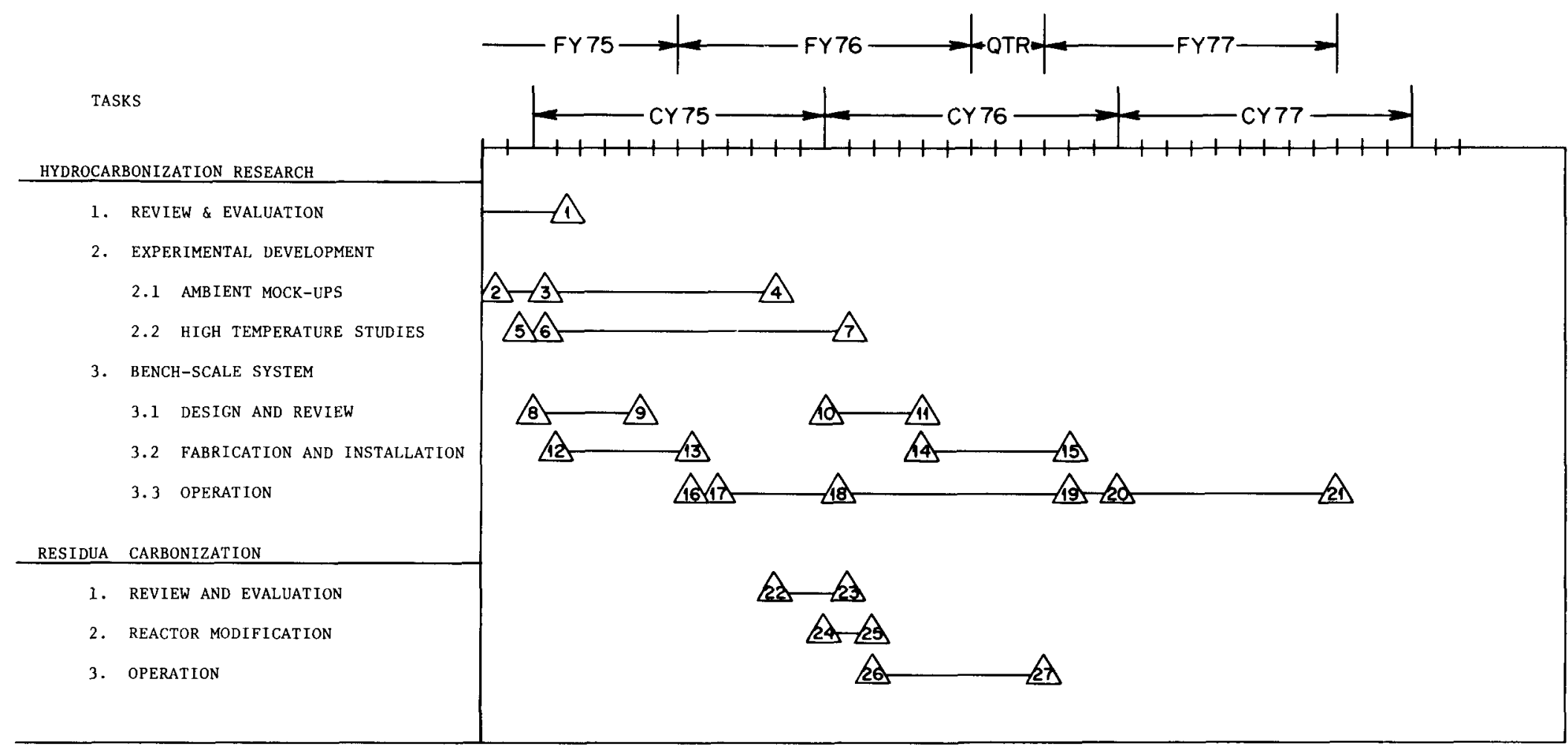

\section{MILESTONES}

- Complete review and evaluation

Begin fluidization and recirculation studies

Begin feeding and solids withdrawal studies

Complete ambient mock-up studies

Began assembly

Begin high temperature operation

. Complete high temperature operation

8. Begin 20 atm design

9. Complete 20 atm design

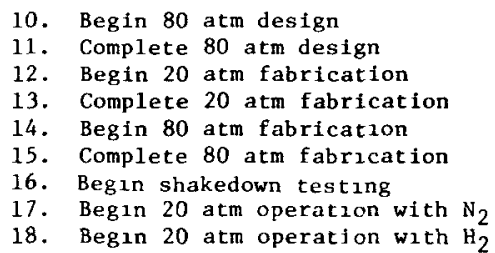

19. Beg1n 80 atm shakedown

20. Begin 80 atm operation with $\mathrm{H}_{2}$

21. Complete 80 atm operation with $\mathrm{H}_{2}$

22. Begin review and evaluation

23. Complete review and evaluation

24. Begin reactor modifications

25. Complete reactor modifications

26. Begin operation

18. Begin 20 atm operation with $\mathrm{H}_{2}$

27. Complete operation

Fig. 2.1. Milestone chart for the hydrocarbonization and residua carbonization projects. 
Table 2.1. Analysis of product gas from run AHC-5

\begin{tabular}{|c|c|c|c|c|c|c|c|c|c|c|c|c|}
\hline & \multicolumn{12}{|c|}{ Sample number } \\
\hline & G2 & G3 & G4 & G5 & G6 & G7 & G8 & G9 & G10 & $\mathrm{G}] 1$ & G12 & G13 \\
\hline Elapsed time, $h r$ & 0.76 & 1.00 & 1.50 & 1.83 & 2.25 & 2.58 & 2.92 & 3.50 & 3.83 & 4.17 & 4.67 & 5.25 \\
\hline Reaction temp., ${ }^{\circ} \mathrm{F}$ & 600 & 800 & 930 & 1100 & 1090 & 1040 & 995 & 995 & 990 & 990 & 935 & 900 \\
\hline \multicolumn{13}{|l|}{ Volume $\%^{\mathrm{a}}$} \\
\hline $\mathrm{CH}_{4}$ & $\operatorname{tr}$ & 1.5 & 13.5 & 10.1 & 2.1 & 0.6 & 0.2 & 0.1 & $\operatorname{tr}$ & $\operatorname{tr}$ & $\operatorname{tr}$ & $\operatorname{tr}$ \\
\hline $\mathrm{C}_{2}{ }^{\prime} \mathrm{s}$ & 0 & 1.3 & 1.5 & 0.5 & 0.3 & 0.1 & tr & $\operatorname{tr}$ & tr & 0 & 0 & 0 \\
\hline $\mathrm{C}_{3}^{\prime} \mathrm{s}$ & 0 & 0.7 & 0.1 & tr & tr & $\operatorname{tr}$ & tr & $\operatorname{tr}$ & tr & $\operatorname{tr}$ & 0 & 0 \\
\hline $\mathrm{C}_{4}^{\prime} \cdot \mathrm{s}$ & 0 & 0.3 & tr & $\operatorname{tr}$ & $\operatorname{tr}$ & tr & tr & 0 & tr & tr & 0 & 0 \\
\hline $\mathrm{C}_{5}{ }^{\prime} \mathrm{s}$ & 0 & 0.2 & $\operatorname{tr}$ & $\operatorname{tr}$ & 0 & 0 & 0 & 0 & 0 & 0 & 0 & 0 \\
\hline $\mathrm{C}_{6}{ }^{\prime s}$ & 0 & tr & & & & & & & & & & \\
\hline Benzene & 0 & tr & 0.2 & tr & tr & $\operatorname{tr}$ & tr & $\operatorname{tr}$ & tr & tr & 0 & 0 \\
\hline Toluene & 0 & $\operatorname{tr}$ & tr & $\operatorname{tr}$ & $\operatorname{tr}$ & $\operatorname{tr}$ & tr & tr & tr & tr & & 0 \\
\hline $\mathrm{H}_{2}$ & $\operatorname{tr}$ & 0.2 & 67.1 & 75.1 & 90.6 & 92.6 & 88.6 & 87.7 & 89.5 & 89.6 & 5.0 & 0.7 \\
\hline $\mathrm{CO}$ & tr & 2.5 & 6.3 & 5.8 & 0.4 & tr & $t r$ & tr & tr & $\operatorname{tr}$ & tr & tr \\
\hline $\mathrm{CO}_{2}$ & 3.0 & 13.7 & 6.2 & 2.5 & 0.2 & $\operatorname{tr}$ & tr & $\operatorname{tr}$ & tr & $\operatorname{tr}$ & tr & $\operatorname{tr}$ \\
\hline $\mathrm{O}_{2}$ & $\operatorname{tr}$ & $\operatorname{tr}$ & tr & tr & tr & $t r$ & tr & 0.1 & $\operatorname{tr}$ & tr & $\operatorname{tr}$ & 0.3 \\
\hline $\mathrm{H}_{2} \mathrm{O}$ & 0.6 & 1.3 & 0.7 & 0.6 & 0.6 & 1.1 & 1.6 & 1.9 & 1.3 & 0.8 & 0.7 & 1.1 \\
\hline $\mathrm{H}_{2} \mathrm{~S}$ & 0 & 0 & $\operatorname{tr}$ & $\mathrm{tr}$ & tr & $\operatorname{tr}$ & tr & tr & $\operatorname{tr}$ & tr & 0 & 0 \\
\hline
\end{tabular}

$a_{\operatorname{tr}}<0.1 \%$ 
Table 2.2. Proximate and ultimate analyses of samples from run $\mathrm{AHC}-5$

\begin{tabular}{lrrr}
\hline & Coal & Char & Tar \\
\hline Proximate analysis (as received), wt \% & & & \\
Volatile matter & 40.9 & 11.2 & 64.9 \\
Moisture & 11.3 & 0.7 & 16.7 \\
Ash & 6.2 & 11.1 & 2.0 \\
Fixed carbon (by difference) & 41.6 & 77.0 & 16.4 \\
Ultimate analysis (maf), wt \% & & & \\
Carbon & 70.8 & 91.1 & 76.3 \\
Hydrogen & 5.3 & 3.3 & 8.3 \\
Nitrogen & 1.0 & 1.2 & 1.2 \\
Sulfur & 0.9 & 0.7 & 0.6 \\
Oxygen (by difference) & 22.0 & 3.7 & 13.6 \\
Higher heating value (maf), Btu/lb & 12,610 & 14,900 & 15,060 \\
\end{tabular}


Table 2.3. Carbon balance on mun AHC-5

\begin{tabular}{lcc}
\hline & Grams of carbon & $\%$ of carbon feed \\
\hline Input & & \\
Coal feed & 1215.3 & \\
Output & & 76.1 \\
Char & 925.3 & 5.0 \\
Tar & 60.3 & 1.9 \\
Scrubber liquid & 23.0 & 19.1 \\
Gas & 232.4 & 102.1 \\
& 1241.0 & \\
\hline
\end{tabular}


Analyses of product gases from the second run with hydrogen as feed gas (run AHC-6) are presented as Table 2.4. The lower apparent methane yields in run AHC-6 in comparison with run AHC-5 indicate that at the lower operating temperature for this run $\left(\sim 1050^{\circ} \mathrm{F}\right)$ cracking of liquid products may have been less severe than in run AHC-5. Proximate and ultimate analyses of feed coal char and tar from run AHC-6 are presented as Table 2.5. Table 2.6 presents a material balance for run AHC-6. Lack of closure is a result of tar and char losses in the line between the reactor and the cyclone.

Three experiments were attempted during the quarter. Run AHC-7, a repeat of run AHC -6 , was aborted because of a plug between the reactor and the cyclone shortly after reactor heat-up began (at about $250^{\circ} \mathrm{F}$ ). Since definite layering of impervious solid was found and since the line had not been cleaned since run $A H C-6$, the bulk of the plug was evidently residue from the previous run, sealed by carryover of fines. Run AHC-8, a second effort to repeat run AHC-6, was completed successfully, and samples were submitted for chemical analysis.

After sampling and clean-up following AHC-9, installation of a recirculating fluidized bed reactor and its associated subsystems was begun. This modification continued at the end of the reporting period and is described separately in the report on the Residua Carbonization project.

Two runs are planned during the next quarter in preparation for the Residua Carbonization project. These runs will utilize the modified reactor containing an axial draft tube.

\subsection{Bench-Scale System}

H. D. Cochran, Jr., G. I. Yoder, and R. I. Andrews

Fabrication and installation

Effort during this quarter was focused on completion of installation and shakedown testing. Intervessel piping was completed, rupture disks were received and installed, and the piping on the scrubber pump was completed. Heaters on the reactor and the preheater were connected and these vessels were insulated. Thermocouples and pressure taps were tied into the instrument panel. 
Table 2.4. Analysis of product gas from run AHC-6

\begin{tabular}{|c|c|c|c|c|c|c|c|c|c|c|c|c|}
\hline & \multicolumn{12}{|c|}{ Sample number } \\
\hline & Gl & G2 & G3 & G4 & G5 & G6 & $\mathrm{G} 7$ & G8 & G9 & $\mathrm{G} 1 \mathrm{O}^{\mathrm{a}}$ & $G] I^{a}$ & $\mathrm{G} 12^{\mathrm{a}}$ \\
\hline Elapsed time, hr & 0 & 0.33 & 0.72 & 1.00 & 1.33 & 1.67 & 2.00 & 2.42 & 2.83 & 3.42 & 3.92 & 4.25 \\
\hline Reaction temp., ${ }^{\circ} \mathrm{F}$ & 75 & 390 & 660 & 840 & 1000 & 1050 & 1050 & 1060 & 1060 & 1050 & 1020 & 1000 \\
\hline \multicolumn{13}{|l|}{ Volume $\%$} \\
\hline $\mathrm{CH}_{4}$ & $\operatorname{tr}$ & $\operatorname{tr}$ & 0.2 & 1.8 & $7 \cdot 3$ & 3.1 & 1.7 & 1.2 & 0.9 & 0.8 & 0.2 & 0 \\
\hline $\mathrm{C}_{2}^{\prime} \mathrm{s}$ & $\operatorname{tr}$ & $\operatorname{tr}$ & 0.1 & 1.6 & 0.9 & 0.2 & 0.1 & 0.1 & 0.1 & $\operatorname{tr}$ & $\operatorname{tr}$ & 0 \\
\hline $\mathrm{C}_{3}{ }^{\prime} \mathrm{s}$ & $\operatorname{tr}$ & $\operatorname{tr}$ & 0.1 & 0.9 & 0.1 & $\operatorname{tr}$ & $\operatorname{tr}$ & $\operatorname{tr}$ & $\operatorname{tr}$ & $\operatorname{tr}$ & $\operatorname{tr}$ & $\operatorname{tr}$ \\
\hline$C_{4}^{\prime} s$ & $\operatorname{tr}$ & 0 & $\operatorname{tr}$ & 0.3 & $\operatorname{tr}$ & tr & $\operatorname{tr}$ & tr & 0 & 0 & 0 & 0 \\
\hline$C_{5}{ }^{\prime} s$ & 0 & 0 & $\mathrm{t} r$ & 0.2 & $\operatorname{tr}$ & $\operatorname{tr}$ & $\operatorname{tr}$ & tr & 0 & 0 & 0 & 0 \\
\hline$c_{6}^{\prime} s$ & 0 & 0 & 0 & tr & 0 & 0 & tr & 0 & 0 & 0 & 0 & 0 \\
\hline Benzene & $\operatorname{tr}$ & tr & $\mathrm{O}$ & $\operatorname{tr}$ & $\operatorname{tr}$ & $\operatorname{tr}$ & tr & $\operatorname{tr}$ & $\operatorname{tr}$ & tr & $\operatorname{tr}$ & $t x$ \\
\hline Toluene & $\operatorname{tr}$ & $\operatorname{tr}$ & $\operatorname{tr}$ & tr & $\operatorname{tr}$ & tr & $\operatorname{tr}$ & $\operatorname{tr}$ & $\operatorname{tr}$ & 0 & tr & 0 \\
\hline $\mathrm{H}_{2}$ & 94.7 & 93.5 & 90.5 & 79.8 & 77.1 & 82.3 & 84.6 & 82.2 & 87.3 & 17.9 & 5.7 & 2.6 \\
\hline $\mathrm{CO}$ & 0 & 0 & & 0 & 1.7 & 3.2 & 1.6 & 0 & 0 & 0 & 0 & 0 \\
\hline $\mathrm{N}_{2}$ & 0.4 & 0.4 & 0.9 & 0.2 & 0.1 & 0.3 & 1.3 & 1.2 & 1.0 & 8.0 & 6.4 & 22.4 \\
\hline $\mathrm{CO}_{2}$ & $\operatorname{tr}$ & tr & $\operatorname{tr}$ & 0 & tr & $\operatorname{tr}$ & $\operatorname{tr}$ & $\operatorname{tr}$ & $\operatorname{tr}$ & 1.0 & 1.2 & 9.2 \\
\hline $\mathrm{H}_{2} \mathrm{O}$ & 1.1 & 0.9 & 2.9 & 1.4 & 0.6 & 2.4 & 2.9 & 6.4 & 2.2 & 2.5 & 1.3 & 4.2 \\
\hline $\mathrm{H}_{2} \mathrm{~S}$ & 0 & 0 & 0 & 0 & $\operatorname{tr}$ & $\operatorname{tr}$ & $t x$ & tr & 0 & 0 & 0 & 0 \\
\hline Ar & 3.3 & 4.4 & 3.4 & 5.4 & 5.3 & 6.3 & 6.2 & 6.3 & 6.0 & 57.3 & 76.1 & 55.5 \\
\hline $\mathrm{He}$ & 0.4 & 0.4 & 0.6 & 2.6 & 3.3 & 3.3 & 3.0 & 2.5 & 2.4 & 12.4 & 9.0 & 6.0 \\
\hline
\end{tabular}

apparent air leak in sample cylinders. 
Table 2.5. Proximate and ultimate analyses of samples from run AHC-6

\begin{tabular}{lrrr}
\hline & Coal & Char & Tar \\
\hline Proximate analysis (as received), wt \% & & & \\
Volatile matter & 42.0 & 12.1 & 78.4 \\
Moisture & 9.7 & 1.1 & 14.3 \\
Ash & 6.7 & 11.3 & 0.8 \\
Fixed carbon (by difference) & 41.6 & 75.5 & 6.5 \\
Ultimate analysis (maf), wt \% & & & \\
Carbon & 72.7 & 91.6 & 75.5 \\
Hydrogen & 5.7 & 3.4 & 9.7 \\
Nitrogen & 1.1 & 1.1 & 0.6 \\
Sulfur & 0.8 & 0.7 & 1.1 \\
Oxygen (by difference) & 19.7 & 3.2 & 13.1 \\
Higher heating value (maf), Btu/lb & 12,470 & 15,110 & 15.590 \\
& & & \\
\hline
\end{tabular}

Table 2.6. Carbon balance on run AHC-6

\begin{tabular}{lcc}
\hline & Grams of carbon & $\%$ of carbon feed \\
\hline Input & & \\
Coal feed & 1227.7 & \\
Output & & \\
Char & 848.0 & 69.1 \\
Tar & 32.2 & 2.6 \\
Scrubber liquid & 29.1 & 2.4 \\
Gas & $\underline{119.8}$ & $\underline{9.8}$ \\
& 1029.1 & 83.9 \\
\hline
\end{tabular}


The Bendix gas chromatograph was installed in the process exhaust line. The sample system was constructed to allow selection of either sample or calibration gas from the control room. Solenoid valves at both the sample inlet and instrument exhaust lines prevent overpressure in the instrument during emergency purge.

Valving for feed gas was completed. Two three-way valves in series first split the incoming gas between the preheater and pneumatic transport line and then provide a temperature trim by allowing a portion of cold gas to by-pass the preheater. The line between the preheater and reactor was trace heated using three $2000-W$ resistance heaters. The connecting piping between the reactor and scrubber was heated with two $2000-\mathrm{W}$ heaters to prevent liquid condensation. These two lines can be operated at 350 psi and $1250^{\circ} \mathrm{F}$. A pressure equalization line was installed on the char overflow leg between the reactor and char receiver. It prevents overstressing the weld at the reactor due to the pressure reaction force at the expansion joint.

A 2-in. ball valve was welded to the top of the feed hopper to facilitate filling with coal. Rupture disks and relief valves on each vessel were connected to a 2-in. header which extends $10 \mathrm{ft}$ above the building roof. A coal flow monitor was fabricated and placed on the pneumatic transport line.

The cold trap was completed with the installation of cooling coils and the coolant circulation system. Temperatures between ambient and about $-70^{\circ} \mathrm{C}$ can be obtained by varying the circulation rate of dry-icetemperature $\left(-78.5^{\circ} \mathrm{C}\right)$ coolant through the coils.

Hook-up of remaining thermocouples and pressure switches was completed. Overtemperature and overpressure alarms, displayed on the panel board, are now operational. Work is nearly completed on the balance of the alarm/emergency shutdown circuitry. Other work on instruments and controls included start-up and successful shakedown testing of the on-line process gas chromatograph, completion of balancing pressure control on the scrubber pump (manual control, which has been used to date, is not practical with hydrogen pressure in the system), and completion and testing of the fire detection sensors in the equipment room.

As a result of difficulties with the coal feeder during the two runs with nitrogen at $20 \mathrm{~atm}$ (reported below), the coal feeder was modified as 
follows: (1) the feed hopper is aerated and pressurized with the gas used for pneumatic transport of feed coal, (2) the packing in the ball valve coal feeder was replaced, and (3) the pneumatic transport gas is directed to impinge on the downstream side of the feeder valve to break up loose compacts in the feeder. Testing of the modified fieeder at atmospheric pressure was completed successfully, and tests at $20 \mathrm{~atm}$ are underway.

Construction of the hydrogen trailer station is very nearly completed; about one week of work remains. Two hydrogen tube trailers, owned by Union Carbide Nuclear Division, have been assigned to this project. The supply station and trailers will be available in time for the first run with hydrogen scheduled for early next quarter.

With the installation work nearly completed, it was possible to conduct several shakedown tests on the system. The system was pressurized at ambient temperature, heated to design conditions at atmospheric pressure, and then operated successfully with nitrogen flow at pressure and temperature. After the spray nozzle in the scrubber had been installed, the scrubber, pump, and heat exchangers were successfully tested. Preparations were completed for the first full operation of the system, but the flanged top of the scrubber had not been adequately resealed, and a substantial leak was evident during start-up. The scrubber flange was resealed and tested successfully.

The first two shakedown runs were completed successfully during November. For these runs $25 \mathrm{Ib}$ of nominal $-50+140$ mesh coal was charged to the feed hopper. (Subsequent particle size analysis indicated a largerthan-expected percentage of -140 mesh fines in the feed charge.)

During the first run the system was brought to 5 atm pressure with nitrogen. The preheater and reactor were then brought to 1250 and $1050^{\circ} \mathrm{F}$, respectively, the system was leak checked, and coal feed at $\sim 5 \mathrm{Ib} / \mathrm{hr}$ was initiated. Difficulties with the orifice flow meter on feed gas precluded accurate flow measurement of control. Consequently, the run was terminated after only about $5 \mathrm{lb}$ of coal had been fed to the reactor.

Several other problems were encountered during the first shakedown run. The most serious was that the coal feed rate appeared to be unstable 
(we had no direct measurement of coal feed rate other than feeder rpm for this first run). There also appeared to be significant fines carryover to the scrubber. Several minor difficulties with process instrumentation were detected and later corrected.

Prior to the second run, the orifice flow meter on the feed gas was inspected and repaired. In addition, a coal flow meter (based on the heat transport principle described earlier) was installed on the coal feed line.

For the second run, the system was again pressurized to 5 atm with nitrogen. The preheater and reactor were then brought to 1250 and $1050^{\circ} \mathrm{F}$, respectively, the system was leak checked, and coal feed was initiated at about $10 \mathrm{lb} / \mathrm{hr}$. The feed gas control was satisfactory, and the coal flow meter performed well. The remaining 20 Ib of coal was transported to the reactor and $\sim 8 \mathrm{lb}$ of char overflowed to the char receiver.

During the second run there was some difficulty with plugging of the pressure taps used to measure differential pressure through the fluidized bed in the reactor. Other parts of the system performed well. No attempt was made to recover products for a material balance, but some qualitative observations were made. The char from the char receiver was free flowing, and the particle size distribution was similar to that of the feed coal. The liquid from the scrubber appeared to contain three phases - a lighter than water phase, an aqueous phase, and a heavy tar phase. The liquid was readily flushed from the scrubber. (The cold trap was not cooled, and only traces of tar were recovered from this vessel.) The filter on the effluent gas was slightly loaded with tar.

During December two further runs were made using nitrogen as feed gas at full system design pressure (20 atm) and design temperatures (1400 and $1250^{\circ} \mathrm{F}$ for the preheater walls and reactor walls, respectively). Both runs were hampered by difficulties in maintaining coal feed. Otherwise, all parts of the bench-scale system operated without problems.

Coal feeding problems appeared to result from bridging in the feed hopper and/or formation of loose compacts of coal in the cavities of the feeder valve. Both phenomena were observed during examination and testing 
of the feeder after the second run. Neither problem had been observed during atmospheric pressure tests or during runs at 5 atm pressure. Several modifications to the feeding system (described above) have been made in an attempt to solve this problem.

It is likely that the feeder problems have been aggravated by the large amount of fines in the feed coal. Earlier tests and runs had been performed with small batches of coal prepared with a small mill and an 8-in.-diam sieve shaker. The hammer mill and 18-in.-diam sieve shaker which were used to prepare the larger batches of coal for the two 20-atm runs produce a feed with a large amount of fines ( 20 wt $\%<10 \mu$ ) which are difficult to remove from the feed. Further tests are planned with the 18-in. sieve shaker to reduce the amount of fines in the feed coal.

Design and review. Design work will be initiated for modification of the system to permit operation at pressures up to 80 atm of hydrogen.

Fabrication and installation. Remaining details of the bench-scale system will be completed during the next quarter.

Operation. One further run with nitrogen at 20 atm pressure is planned to demonstrate satisfactory operation of the full system including the coal feeder. Complete data acquisition and sample analysis will be performed to permit calculation of a material balance. First operation of the system with hydrogen is scheduled to follow this nitrogen run immediately. The balance of the next quarter will be devoted to acquisition of data during operation with hydrogen.

\subsection{Residua Carbonization}

J. B. Gibson and H. D. Cochran, Jr.

This project for supporting research and development on residua. carbonization is supported by the Division of Coal Conversion and Utilization of ERDA. The work in the year beginning November 1, 1975, consists of three tasks: (1) a review and evaluation of experience with the low temperature carbonizer in the Cresap, West Virginia, pilot plant, 
(2) modification of an existing reactor to permit continuous feed of solids-laden residua, and (3) operation of the reactor with three feedstocks (vacuum distillation bottoms from the H-Coal process and solvent extraction underflows from SRC and CSF product liquids) at three temperatures up to $1200^{\circ} \mathrm{F}$.

The two objectives of this project are as follows:

(1) Modify and utilize an existing atmospheric hydrocarbonization reactor for this work.

(2) Establish optimum temperature and feed rates for recovering 90\% of volatile material contained in $\mathrm{H}$-Coal vacuum distillation residuum and SRC and CSF solvent extraction underflows.

The scope of the project is limited as follows:

(1) This project is restricted to operation of a single bench-scale Puidized-bed carbonization reactor.

(2) The fluidizing gas will not contain hydrogen.

(3) No work will be performed beyond that required in evaluating samples provided by FRDA/EE.

(4) Background studies, analyses, and supporting experiments will be restricted to those required to operate the reactor and interpret results.

During the past quarter, work began on the residua carbonization project. Design and operational data from the Cresap (CSF) carbonizer were reviewed. Literature reviewed included the appropriate sections of the 116 monthly reports of the Cresap project and OCR R\&D Reports Nos. 39, $45,50,62$, and 70 .

Modifications to the design of the bench-scale reactor to allow for the continuous residua feed and a recirculating fluidized bed were established. The reactor design can accommodate either a siurry feed or a feed stream of finely ground solids. The reactor is currently designed for batch operation with respect to char; however, with little modification, it can be made continuous with respect to char. 
Modifications to the bench-scale reactor and installation of the modified reactor have been completed. A second preheater, fabricated of $100 \mathrm{ft}$ of coiled tubing in a clam shell heater, will be used to heat the gas stream which fluidizes the downcomers of the reactor. Designs of a feed system and a char overflow pot are essentially complete and fabrication will start shortly. The char overflow pot will allow continuous operation of the reactor with respect to char. Continuous operation is necessary for runs that last more than one to two hours. The char level will be determined by connecting the char overflow pot to one of two overflow legs and plugging the other leg. Finely ground particles of residua will be fed via pneumatic transport from the feed vessel to the reactor. Figure 2.2 is a simplified flowsheet of the residua carbonization experiment showing the modified reactor, the pneumatic feeding system, and the second preheater. Figure 2.3 shows the modified reactor, and Figs. 2.4 and 2.5 show details of the draft tube assembly and distributor plate for the modified reactor.

A second feed system is being investigated in case the first one should prove to be unsuccessful. This second feed system consists of mixing the residua with toluene to form a slurry which is 25 to $50 \%$ toluene by weight. The slurry would then be pumped and sprayed into the reactor.

\section{Work forecast}

The first draft of the review and evaluation of the Cresap carbonizer will be completed. Fabrication and installation of the feed vessel and char overflow pot will be completed. Operation will be initiated using pulverized H-Coal vacuum distillation bottoms, pneumatically transported to the reactor.

\subsection{References for sect. 2}

1. J. M. Holmes et al., Hydrocarbonization Research Phase I Report: Review and Evaluation of Hydrocarbonization Data, ORNL-TM-4835 (August 1975). 


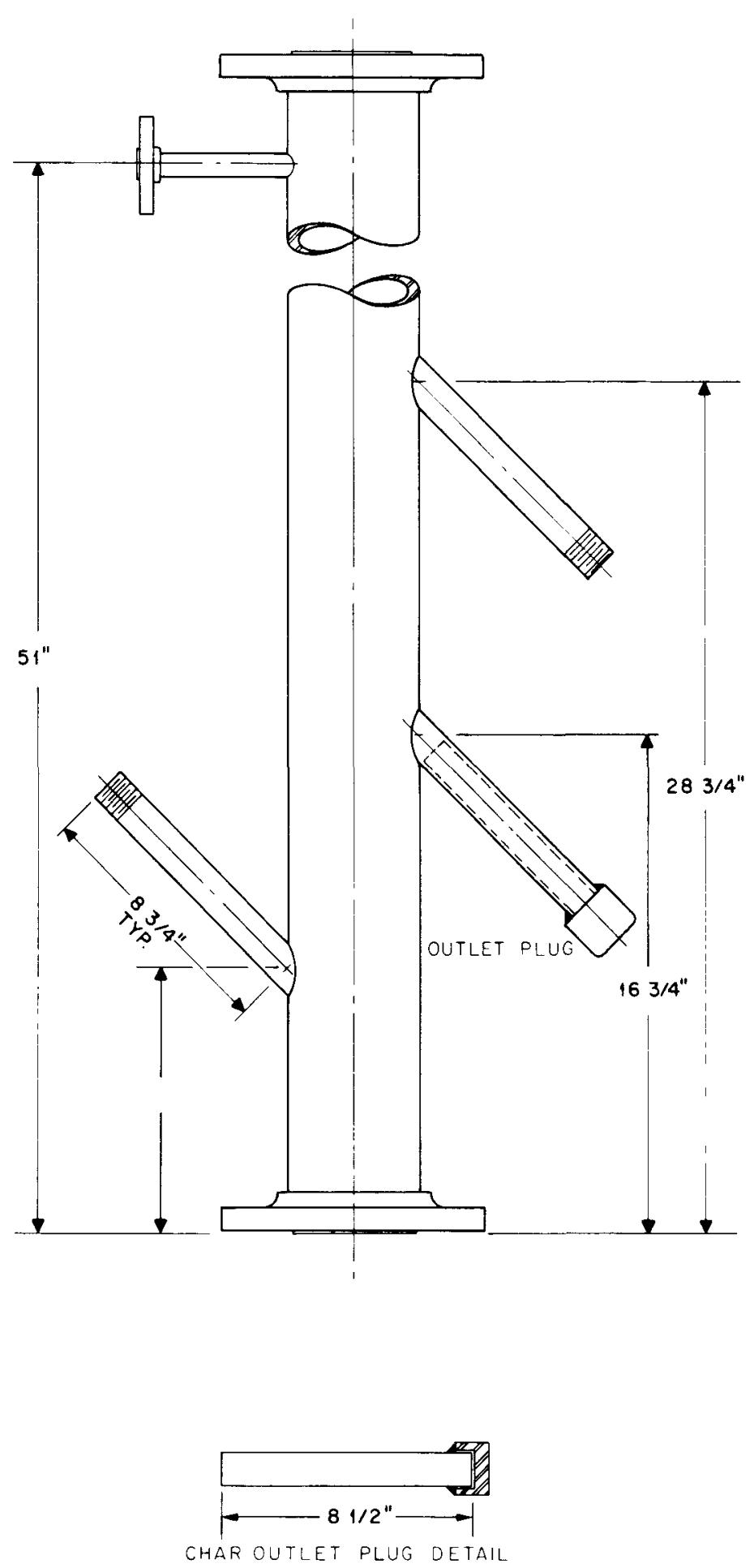

Fig. 2.3. Residua carbonization reactor. 


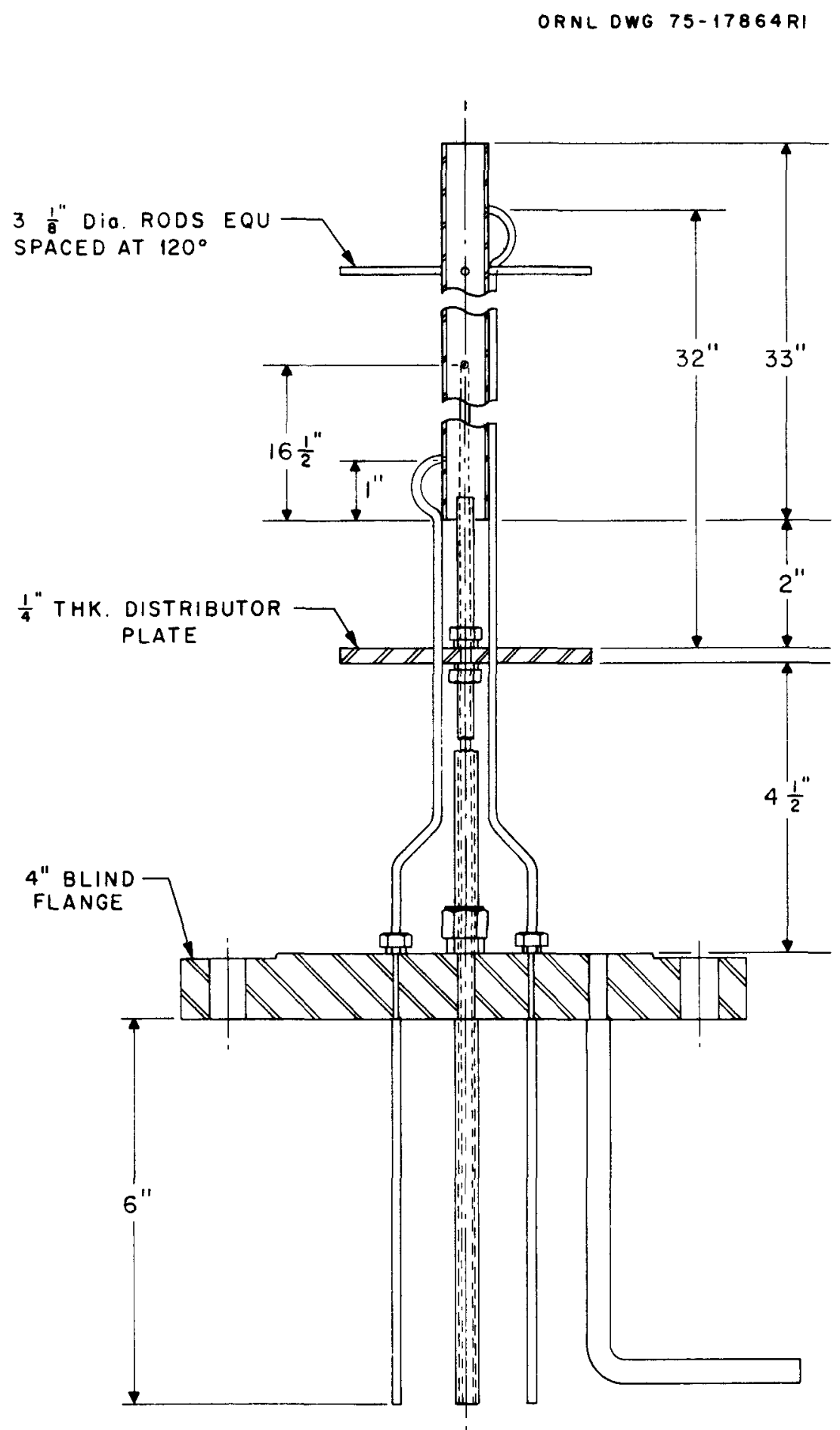

Fig. 2.4. Residua carbonization reactor draft tube details. 
ORNL DWG 75-17480

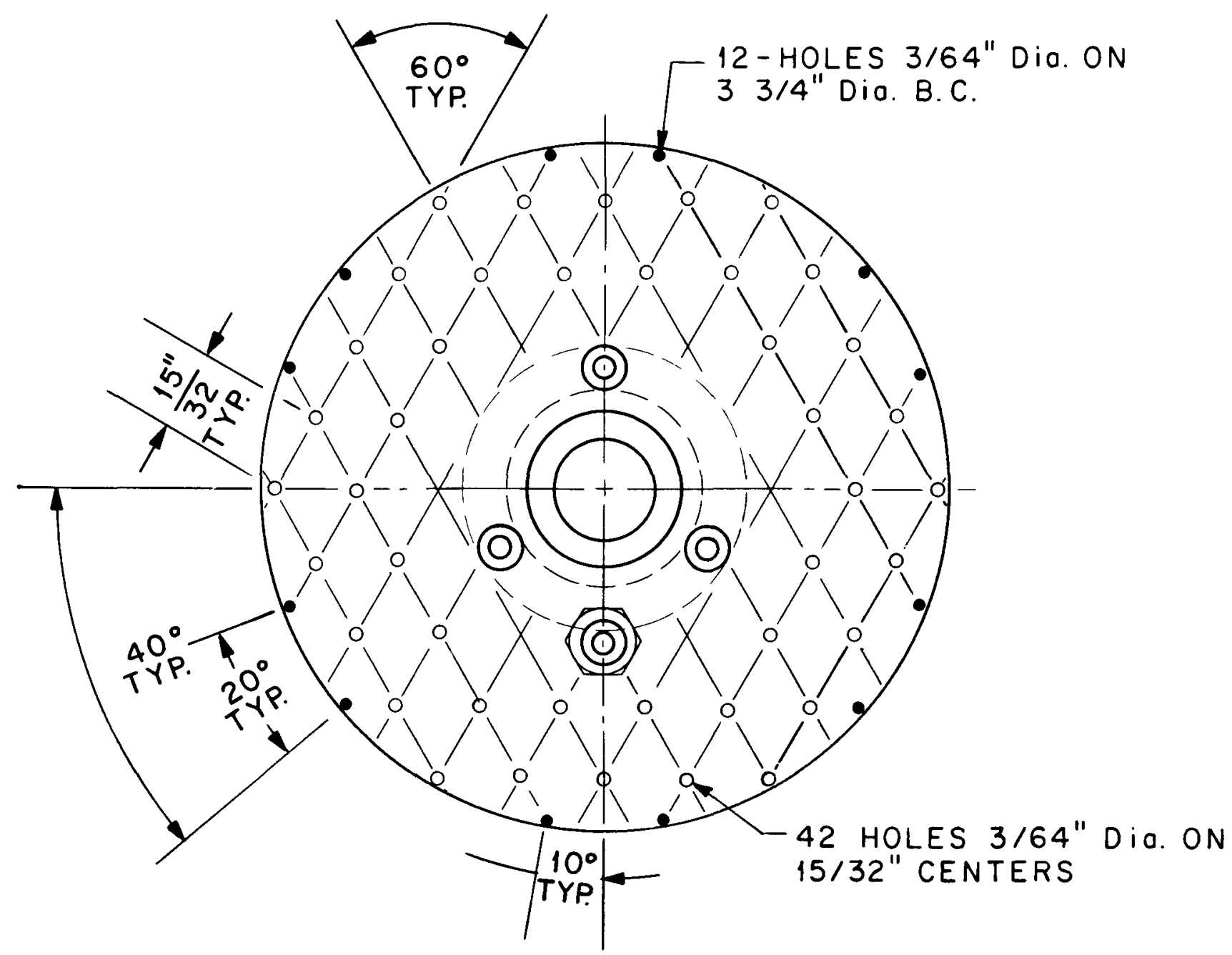

Fig. 2.5. Residua carbonization distributor plate. 


\section{SUPPORTING RESEARCH AND DEVELOPMEITT}

IN SEPARATIONS TECHNOLOGY

\section{B. R. Rodgers}

This project for supporting research and development in separations technology for coal conversion systems is sponsored by the Division of Fossil Energy Research of ERDA. The work in the first year focused on alternative methods for accomplishing the solid-liquid separations that are required for liquefaction processes. The first phase, completed January 18, 1975, consisted of the review and evaluation of available data. Phase II, reviewed June 30, 1975, consisted of characterization tests of selected process streams and scouting tests for some alternate separations methods. A third phase has begun which includes bench-scale development of a solvent-agglomeration/fractionation separations technique, verification of methods to significantly improve current process filtration rates, and selected characterization and ageing tests.

$\underline{\text { Summary }}$

Reported accomplishments during this period cover five areas: batch settling, continuous settling, additive agglomeration, bench-scale development, and characterization of coal-derived process materials.

Batch settling studies covered ranges of solvent concentrations in Solvent Refined Coal (SRC) unfiltered oil (UFO) from zero to $20 \%$, and temperatures from 150 to $250^{\circ} \mathrm{C}\left(302\right.$ to $\left.482^{\circ} \mathrm{F}\right)$. These tests failed to find the optimum combination of these variables; the best results were obtained at $150^{\circ} \mathrm{C}$ and $20 \%$ toluene concentration, a corner of the experimental matrix. It is planned to continue these lab-scale tests using the bench-scale apparatus.

Continuous settling studies were initiated to evaluate some parameters of a continuous flow system. Only a small amount of data has been obtained, and these studies will have low priority in the experimental plan. When these studies are completed, the lab-scale data will be used to make an economic evaluation of a continuous settling operation. 
Additive agglomeration studies using solid additives have been an ongoing low priority effort since April 1975. Tests of 15 solid materials have failed to yield positive results to date, and the effort with these materials has been abandoned. However, excellent results were obtained this quarter using liquid additives designed for the petroleum industry. Twenty-four proprietary additives were tested; one gave excellent clarification of upper fractions from a settling test, and three others gave good clarification. The results appear to be valid over a range of temperatures.

Construction of the 1-liter bench-scale apparatus was completed. Pneumatic pressure tests revealed a few inadequacies, and these were corrected. The integrity of the apparatus was tested at 300-psig air pressure (110\% design pressure) for $1 \mathrm{hr}$. Preliminary operation tests using filtered oil verified the operability of other system components such as heaters, controllers, recorders, etc. The initial test with SRC-UFO indicated that settling characteristics of this material in the bench-scale apparatus were similar to those obtained with the lab-scale apparatus.

Characterization studies of SRC oils this quarter include ageing tests, electron microscope particle size distributions, gel permeation chromatography, viscosity-temperature measurements, and vapor pressure measurements. Spectrographic analyses were made of Illinois \#6 and Pittsburgh \#8 coals.

\subsection{Batch Settling studies}

P. R. Westmoreland, S. Katz, B. R. Rodgers, and D. A. McWhirter

Sedimentation studies have shown ${ }^{1}$ that settling under prescribed conditions produces clarified overflows which are free of the contaminants sulfur and ash. The rate of settling has been shown to be a function of temperature and certain solvents; toluene has been shown to improve rates. Also, it recently has been reported ${ }^{2}$ that certain 
chemical additives at low concentrations (< $1000 \mathrm{ppm})$, will significantly increase settling rates. The studies reported in this section elucidate the effects of toluene concentration and temperature programing on settling. The additive agglomeration studies are reported in sect. 3.3. Optimization of Solvent-to-Oil Ratio for Batch Settling of Toluene/SRCUFO Mixtures

Initially, experiments to optimize solvent-to-oil (s/O) ratios made use of subsequent filtrations to determine the efficacy of solvents at a given concentration. However, the effects of settling during the filtration clouded the results, and interpretation was difficult. To avoid this problem, a double tube was used. First, solids were allowed to completely settle in the upper tube. Then, the settled mixture was filtered with the lower tube. Ideally, this procedure would simulate filtration of settler bottoms and, if continued to completion, would also provide information on flow of clarified filtrate through a packed filter cake. This route proved unsatisfactory for the lab-scale experiments because of the length of time required per experiment ( $\sim 24$ hours). A simple settling at a given temperature, followed by microscopic examination and chemical analyses, was finally adopted as the best method to characterize solvent effects on solids separation. This test proved to be rapid, free from interferences, and accurate ash analyses of selected fractions provided a good measure of particle sedimentation. The test as finally adopted consisted of heating approximately $175 \mathrm{~g}$ of liquid rapidly to temperature ( $10 \mathrm{~min}$ ), maintaining temperature for $60 \mathrm{~min}$, quenching in a cold water bath, and finally dividing into 10 or 11 fractions for ash analyses.

A partial matrix of I-hr settling experiments was performed at toluene concentrations of $0,5,7.5,10,15$, and 20\%, and at temperatures of 150,200 , and $250^{\circ} \mathrm{C}$. Chemical analyses of samples from these tests are summarized in Table 3.1. Judging the settling effectiveness by the ash and sulfur content in upper and lower fractions, the best results were obtained at $150^{\circ} \mathrm{C}$ and $20 \%$ toluene, a corner of the matrix. This indicates that better combinations of solvent concentration and temperature may be outside the range of these experiments, and that further experiments are necessary to determine optimum conditions. 
Table 3.1. Ash and sulfur analyses for toluene optimization experiments

(Ash \%, followed by sulfur \% in parentheses. Some duplicate runs.)

\begin{tabular}{|c|c|c|c|c|c|c|c|}
\hline \multirow{2}{*}{$\begin{array}{l}\text { Settling } \\
\text { temperature }\end{array}$} & \multirow{2}{*}{$\begin{array}{l}\text { Depth } \\
\text { fraction } \\
\text { number }\end{array}$} & \multicolumn{6}{|c|}{ Toluene concentration in blend with SRC unfiltered oil } \\
\hline & & $0 \%$ & 54 & $7.5 \%$ & $10 \%$ & $15 \%$ & $20 \%$ \\
\hline $150^{\circ} \mathrm{C}$ & $\begin{array}{c}1 \\
2 \\
3 \\
4 \\
5 \\
6 \\
7 \\
8 \\
9 \\
10 / 11\end{array}$ & & & & $\begin{array}{c}2.56(0.94) \\
2.57 \\
2.68 \\
3.80 \\
2.77(0.93)\end{array}$ & $\begin{array}{c}0.91(0.65) \\
0.87 \\
0.92 \\
5.87 \\
4.91(0.96)\end{array}$ & $\begin{array}{c}<0.03(0.59) \\
<0.03 \\
<0.03 \\
4.43 \\
8.38(1.45)\end{array}$ \\
\hline $200^{\circ} \mathrm{C}$ & $\begin{array}{c}1 \\
2 \\
3 \\
4 \\
5 \\
6 \\
7 \\
8 \\
9 \\
10 / 11\end{array}$ & $\begin{array}{c}2.82(0.81) \\
2.76 \\
2.99 \\
4.52(1.00)\end{array}$ & $\begin{array}{c}2.08,2.45(0.81,0.82) \\
2.38,2.48 \\
2.45,2.46 \\
2.61,2.54 \\
3.11,2.98(0.86,0.87)\end{array}$ & $\begin{array}{c}2.49(0.71) \\
2.52 \\
2.60 \\
2.87 \\
3.89(0.84)\end{array}$ & $\begin{array}{c}2.46,2.63(0.68,0.77) \\
2.56,2.75 \\
2.54,2.76 \\
2.67,2.85 \\
3.24,5.74(0.74,0.85)\end{array}$ & $\begin{array}{c}2.44,2.18(0.74,0.64) \\
2.32,2.28 \\
2.37,2.36 \\
2.48,2.43^{*} \\
4.81,4.54^{a}\left(0.93,0.79^{a}\right)\end{array}$ & $\begin{array}{cc}0.51, & 0.07(0.61,0.55) \\
0.38,0.07 \\
0.41,0.07 \\
\\
2.52,5.53 \\
7.48,8.06(1.23,1.10)\end{array}$ \\
\hline $250^{\circ} \mathrm{C}$ & $\begin{array}{c}1 \\
2 \\
3 \\
4 \\
5 \\
6 \\
7 \\
8 \\
9 \\
10 / 11\end{array}$ & & $\begin{array}{c}2.38(0.80) \\
2.71 \\
2.61 \\
2.75 \\
4.08(0.85)\end{array}$ & $\begin{array}{c}.11(0.80) \\
4.04 \\
2.60 \\
2.70 \\
4.90(0.95)\end{array}$ & $\begin{array}{c}2.75(0.75) \\
2.81 \\
3.59 \\
2.74 \\
4.31(0.92)\end{array}$ & $\begin{array}{c}1.97(0.66) \\
2.02 \\
2.09 \\
2.21 \\
5.78(0.92)\end{array}$ & \\
\hline
\end{tabular}

ONine fractions of oil were removed; analyses 7 and 9 are entered in 8 and 10 slots. 
Low temperatures, such as $150^{\circ} \mathrm{C}$ would be an advantage from a process design viewpoint by permitting settling at lower pressures. Figure 3.7 in Section 3.5 shows that the total pressure over a $20 \%$ toluene blend at $150^{\circ} \mathrm{C}$ was $30 \mathrm{psig}$. By comparison, total pressure over the unfiltered oil at $345^{\circ} \mathrm{C}$, the temperature necessary for comparable settling without solvent, was $75 \mathrm{psig}$ and increasing rapidly with temperature. Possible drawbacks to high-toluene, low-temperature operations would be inefficient toluene recovery and poor separation of the liquid from the solid. An economic evaluation showed that for toluene recoveries of $95 \%$ or greater from a $20 \%$ toluene-in-oil blend, agglomeration/fractionation exhibits a sizeable cost advantage over pressure precoat filtration. Both toluene recovery and product liquid recovery will be further investigated on the bench-scale apparatus.

SettIing of Toluene/SRC Mixtures with Temperature Programming

A temperature-programmed run (approx $2^{\circ} \mathrm{C} / \mathrm{min}$ ) using 9 and $20 \%$ toluene/ SRC mixtures, was made to temperatures of 300 and $260^{\circ} \mathrm{C}$, respectively. This was followed by a descending temperature program at a similar rate. The resulting mixture was divided into 10 fractions, and selected fractions were analyzed for sulfur, ash, and iron. The results are shown in Table 3.2. The bottom fractions from the $9 \% \mathrm{mix}$ were very viscous liquids, but the bottoms from the $20 \%$ mix was a relatively dry solid. The latter indicates (and Table 3.2 verifies) that settling was rapid and complete. The analyses show low concentrations of ash and sulfur in the upper zones of both runs, but the $20 \%$ toluene temperature-programmed experiment gave some of the lowest ash and sulfur values obtained to date.

Table 3.2. Analyses of fractions from temperatureprogramed settling

\begin{tabular}{ccccr}
\hline $\begin{array}{c}\text { Toluene } \\
\text { content }\end{array}$ & $\begin{array}{c}\text { Fraction } \\
\text { number }\end{array}$ & $\begin{array}{c}\text { Ash } \\
(\text { wt \%) }\end{array}$ & $\begin{array}{c}\text { Sulfur } \\
\text { (wt \%) }\end{array}$ & $\begin{array}{r}\text { Iron } \\
\text { (ppm) }\end{array}$ \\
\hline 9 & 4 & 0.23 & 0.67 & 29 \\
9 & 7 & 4.70 & 1.02 & 5200 \\
9 & 10 & 7.54 & 1.10 & 8200 \\
20 & 4 & 0.04 & 0.51 & 22 \\
20 & 7 & 0.60 & 0.55 & 710 \\
20 & 10 & 10.31 & 1.36 & 13,900
\end{tabular}




\subsection{Semicontinuous Settling Studies}

S. Katz and B. R. Rodgers

The encouraging results from batch settling experiments prompted laboratory-scale studies to determine some parameters of a continuous flow system. A dynamic settling system has been constructed (Fig. 3.1) which will permit continuous feed and overhead removal at various conditions of feed flow rate and temperature. The feed pot is a 500-cc closed stainless steel container fitted with a mechanical stirrer through a Teflon gland. Feeding of unfiltered coal-derived liquid is accomplished by using nitrogen pressure as the driving force. The settling chamber, a 2.54-cm-ID stainless steel tube, $44 \mathrm{~cm}$ in length, is immersed in a silicone oil heating bath. The feed line enters the settling chamber at a point $9.6 \mathrm{~cm}$ from the top of the settler, giving a settler volume above the feed point of $41.8 \mathrm{cc}$. Flow rate of overhead "product" leaving the top of the settling chamber is controlled with a needle valve. Preliminary runs made with SRC-UFO indicate that operation is satisfactory for short residence times; long residence times will require an improvement in flow control. The information obtained from these studies will provide input for the preliminary economic evaluation of the agglomeration/settling process, which is due during the latter part of this fiscal year.

\subsection{Additive Agglomeration Studies}

S. Katz and B. R. Rodgers

A screening study of the use of chemical additives to improve the agglomeration-settling process was begun in April of 1975. Significant results have been obtained this quarter using liquid additives designed for the petroleum industry. Since very little is known about the mechanism by which these agents operate, initial results have been interpreted by the use of a short settling test at conditions which produce little settling for SRC-UFO alone; thus, any measured improvement is due to the additive. After settling the mixture for $60-70 \mathrm{~min}$ at $280-290^{\circ} \mathrm{C}$, it is separated into ten portions, and selected portions are analyzed for ash. 
ORNL DWG 76-93

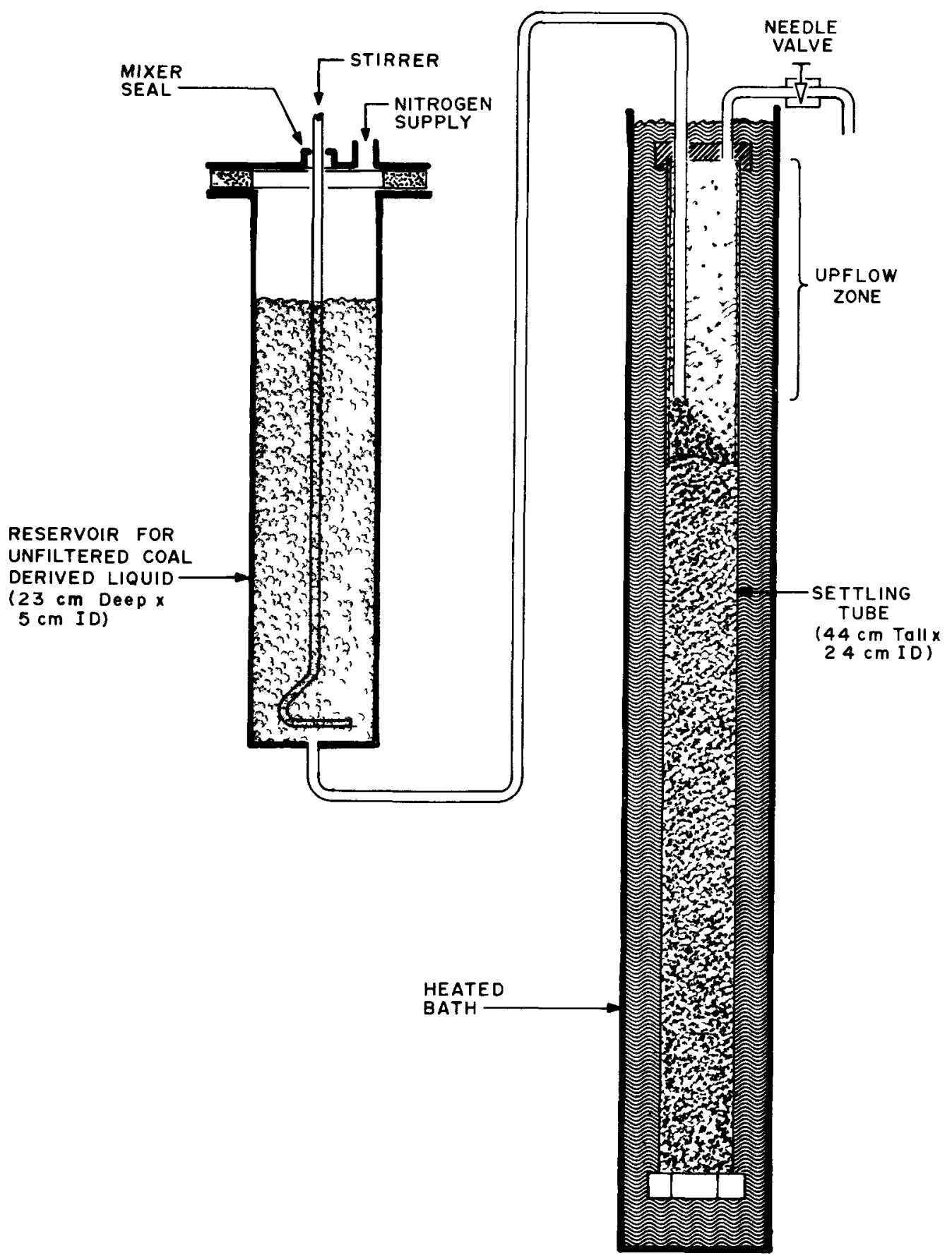

Fig. 3.1. Dynamic flow lab-scale settler. 
The following solid materials gave results which were comparable to SRC-UFO without additive: Polox WSR-301 (Monsanto Co.), Tween-80 (ICI America Inc.), CAL-FLOC Coagulant (Calgon Co.), 2C-304 (Zimmerite Corp.), ENDCOR-4622 (Dearborn Chemical Co.), Sodium Nitrate-Borate (Calgon Co.), Aerosol OT, Sodium Phosphate, Potassium Carbonate, Calcium Sulfate, Ammonium Borate, Sulfur, and 200-250 mesh Illinois \#6 coal (3.5 g added). The poor results of these solid additive tests do not justify further experimentation with similar materials. Except for tests currently underway, no further testing of solid additives is planned.

Screening studies were continued with the testing of 24 liquid additives provided by the Tretolite Division of Petrolite Corporation. Three broad classifications of additives were studied: anionic, cationic, and non-ionic. Other materials tested included metal-organic salts, hydrocarbon copolymers, and crypto-cationic/nonionic additives. Ash analyses of selected fractions from each of the 24 tests were used to determine the degree of settiing. The results produced by the most promising additives after 60 minutes settling time are shown in Table 3.3 . The results show excellent separations at concentrations as low as 500 ppm additive, and in the relatively short time of one hour.

Table 3.3. Settling of SRC-UFO treated with petroleum additive $\left(T=280^{\circ} \mathrm{C}\right)$

\begin{tabular}{cccc}
\hline $\begin{array}{c}\text { Additive } \\
\text { number }\end{array}$ & \multicolumn{3}{c}{ Ash analyses in top fraction } \\
& for different & concentrations of additive (wt \%) \\
\hline 13 & 0.18 & $1000 \mathrm{ppm}$ & $500 \mathrm{ppm}$ \\
14 & 0.023 & 0.11 & 0.11 \\
15 & 0.032 & $<0.05$ & 0.05 \\
21 & 0.093 & 0.88 & 0.36 \\
\hline
\end{tabular}

The most promising additive (14) appears to provide at least a factor of five improvement over the agglomeration-settling time of untreated oils at the same temperature. 
The results of further study of concentration and temperature effects at a reduced settling time of $48 \mathrm{~min}$ are shown in Table 3.4. The results shown in this tabulation are preliminary. Although they appear consistent, repeatability was poor and further substantiation of the absolute values is necessary. An effort is underway to verify these results on the bench-scale apparatus. If similar results are obtained there, the agglomeration of solids by additives, one of the original goals of the project, will provide a simple, inexpensive solution to the solids-liquid separations problem.

Table 3.4. Temperature and concentration effects on settling of additive 14 and SRC-UFO mixtures for $48 \mathrm{~min}$

\begin{tabular}{ccccc}
\hline $\begin{array}{c}\text { Temperature of } \\
\text { test }\left({ }^{\circ} \mathrm{C}\right)\end{array}$ & \multicolumn{4}{c}{$\begin{array}{l}\text { Wt \% ash in the top fraction for the } \\
\text { concentrations of additive } 119\end{array}$} \\
\cline { 2 - 5 } shown \\
\hline 210 & 0.04 & 4.79 & 5.61 & 2.60 \\
245 & 0.04 & 3.85 & 5.39 & 2.49 \\
280 & 0.03 & 2.44 & 5.35 & 2.02 \\
315 & 0.02 & 0.06 & 1.56 & 2.38 \\
350 & 0.04 & 0.06 & 2.50 & 2.50 \\
\hline
\end{tabular}

\subsection{Bench-Scale Development}

B. R. Rodgers and D. A. McWhirter

The bench-scale apparatus described in reference 3 was debugged and pressure tested to 330-psig air pressure. Initial tests with SRCfiltered oil (SRC-FO) demonstrated operability. A settling test at 280$290^{\circ} \mathrm{C}$ using SRC-UFO was completed, and the results of ash determinations on selected fractions are shown in Table 3.5; see Fig. 3.2 for fraction identification (valves are numbered l-8 from top to bottom). The resulting ash concentrations were slightly higher than those obtained with the labscale apparatus. Future plans include testing the new agglomerating additives in SRC-UFO, followed by solvent/SRC-UFO tests. 
Table 3.5. Results of bench-scale settling of SRC-UFO at $280-290^{\circ} \mathrm{C}$

\begin{tabular}{ccc}
\hline $\begin{array}{c}\text { Time sample } \\
\text { withdrawn (min) }\end{array}$ & Valve No. & Ash content \\
\hline 5 & 4 & 0.65 \\
5 & 5 & 0.97 \\
5 & 6 & 1.16 \\
5 & 7 & 1.18 \\
5 & 8 & 5.05 \\
30 & 4 & 0.98 \\
30 & 5 & 1.54 \\
30 & 6 & 1.36 \\
30 & 7 & 1.06 \\
30 & 8 & 5.44 \\
60 & 4 & 1.14 \\
60 & 5 & 1.63 \\
60 & 6 & 1.64 \\
60 & 7 & 2.87 \\
60 & 8 & 6.22 \\
\hline
\end{tabular}

\subsection{Characterization Studies}

B. R. Rodgers, S. Katz, and D. A. McWhirter

Analyses of coal liquefaction process streams have engendered large quantities of data, but little attention has been given to the effect of sampling techniques and ageing on the results. The effect of sampling will be ascertained by comparing "on site" analyses of SRC liquids by Catalytic, Inc. to those at ORNL after the samples have been confined and transported in drums or steel cans. The effect of ageing will be determined by bi-monthly analyses of samples from the SRC (Wilsonville) process streams before and after the filtration section. The effect of storing the samples in steel cans at room temperature, $30^{\circ} \mathrm{F}$, and $140^{\circ} \mathrm{F}$; and at room temperature with a $\mathbb{N}_{\overparen{2}}$ blanket will be determined. Other reported characterization studies of SRC filtered and unfiltered oils include electron microscope particle size distributions, vapor pressure measurements, gel permeation chromatography, and viscosity-temperature relationships.

\section{Ageing Tests}

Analytical results from the first samples submitted for ageing tests revealed an error in the shipment and labeling of samples from the 
ORNL DWG $75-5373$

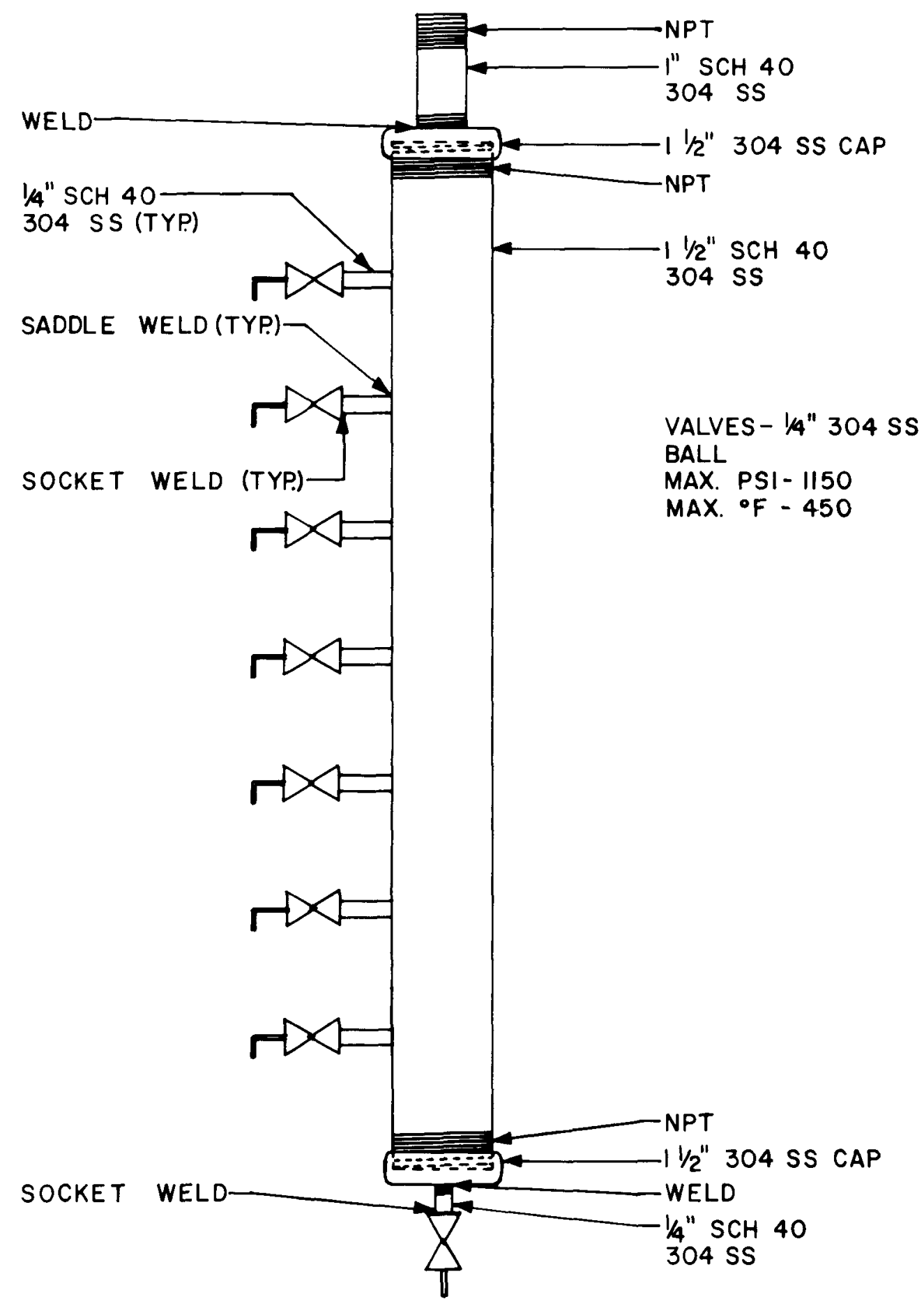

Fig. 3.2. Settling chamber. 
SRC pilot plant at Wilsonville, Alabama. The samples were labeled to indicate that they were unfiltered and filtered oil from a plant run when the coal feed was Pittsburgh \#8 coal. The initial analyses revealed that both samples were filtered oil. Thus, the base-line analyses for November 1975 constitute four determinations on a filtered oil sample. A drum of unfiltered oil, which is reported to be from the same run as the previous samples, has been received and the contents analyzed.

The average results of the four determinations on SRC-FO at the beginning of the ageing period (September 1975) are shown in the first column of Table 3.6 along with the standard deviations. Also shown are results of tests after two months ageing of these samples under various conditions. The filtered oil analyses that varied by more than twice the standard deviation $(\sigma)$ are marked with an asterisk. Overall, there was little change, but significant decreases (greater than $\pm 2 \sigma$ ) occurred in the hydrogen, nitrogen and sulfur contents, as well as in the density. Significant increases were recorded in the viscosity, acetone insolubles, and calorific values. A significant increase in the oxygen content of the sample stored at $30^{\circ} \mathrm{F}$ was also noted. The unfiltered oil from the Pittsburgh \#8 coal had a higher $\mathrm{C} / \mathrm{H}$ ratio than the filtered oil. The same was true for the oils from Illinois \#6 coal, which were not as saturated as the oils from the Pittsburgh coal, and which had higher viscosities and densities.

Electron Microscope Characterization of Solid Particles

Figure 3.3 is an electron micrograph of the particles contained in SRC/UFO from a Pittsburgh \#8 coal. Figure 3.4 gives the particle size distribution of these solids. Although $90 \%$ of the particles have diameters less than 2.7 microns, this sample contained larger particles than the SRC-UFO from Illinois \#6 coal; particles in the latter sample were distributed $90 \%<1.61 \mu, 50 \%<0.99 \mu$, and $10 \%<0.25 \mu$.

A sample of SRC-UFO derived from Illinois \#6 coal was examined by an electron microscope before and after heating for $I \mathrm{hr}$ at $300^{\circ} \mathrm{C}$. The electron microscope at 24,000X and 48,000X magnifications showed that the unheated SRC-UFO sample consisted of a broad range of particle sizes, some with diameters as small as $0.01 \mu$. The particles with diameters near 
Table 3.6. Ageing analyses for oils from the Solvent Refined Coal process

\begin{tabular}{|c|c|c|c|c|c|c|c|c|}
\hline & FO-P\# $8^{\mathrm{a}}$ & FO-P\#8 & FO-P\#8 & FO-P\#8 & FO-P\#8 & FO-I\#6 & UFO-P\#8 & UFO-I\#6 \\
\hline Storage time (months) & 0 & 2 & 2 & 2 & 2 & 0 & 0 & 0 \\
\hline Storage condition & as received & $140-A$ & $30-A$ & $70-A$ & $70-N$ & as received & as received & as received \\
\hline Carbon $^{c}$ (wt $\phi$ ) & $88.1 \pm 0.3^{x}$ & 88.5 & 87.8 & 88.2 & 88.6 & 89.0 & 86.3 & 88.0 \\
\hline Hydrogen ${ }^{c}$ (wt $\left.\phi\right)$ & $8.05 \pm 0.21$ & 8.02 & $7.60 *$ & $7.73^{*}$ & $7.79^{*}$ & 7.46 & 7.14 & 6.71 \\
\hline $\mathrm{C} / \mathrm{H}$ & $11.0 \pm 0.3$ & 11.0 & $11.6 *$ & 11.4 & 11.4 & 11.9 & 12.1 & 13.1 \\
\hline Nitrogen ${ }^{c}$ (wt $\%$ ) & $0.82 \pm 0.01$ & $0.73^{*}$ & 0.81 & 0.81 & $0.78 *$ & 0.66 & 0.93 & 1.04 \\
\hline Oxygen $^{c}$ (wt $\%$ ) & $2.66 \pm 0.50$ & 2.45 & 3.44 & 3.00 & 2.49 & 2.43 & 4.97 & 3.35 \\
\hline Total sulfur ${ }^{c}$ (wt $\%$ ) & $0.42 \pm 0.03$ & $0.34 *$ & $0.32^{*}$ & $0.31 *$ & $0.34^{*}$ & 0.45 & 0.65 & 0.93 \\
\hline Sulfate sulfur (wt $\phi$ ) & $<0.003$ & 0.004 & $<0.003$ & $<0.003$ & 0.003 & - & $<0.02$ & - \\
\hline Sulfide sulfur (wt $\%$ ) & 0.011 & 0.007 & 0.006 & 0.005 & 0.004 & - & 0.13 & - \\
\hline Ash (wt $\%$ ) & 0.02 & 0.02 & 0.02 & 0.02 & 0.02 & $<0.05$ & 2.52 & 3.19 \\
\hline Density $(\mathrm{g} / \mathrm{cc})$ & $1.056 \pm 0.001$ & 1.054 & $1.052^{*}$ & $1.052^{*}$ & $1.053^{*}$ & - & 1.114 & 1.141 \\
\hline Viscosity $\left(\mathrm{cP} @ 250^{\circ} \mathrm{F}\right)$ & $1.441 \pm 0.003$ & $1.468 *$ & $1.450 *$ & $1.458 *$ & $1.450^{*}$ & - & $52.7 @ 100^{\circ} \mathrm{F}$ & $295 @ 100^{\circ} \mathrm{F}$ \\
\hline $\begin{array}{l}\text { Solids - acetone } \\
\text { insolubles (wt \%) }\end{array}$ & $2.60 \pm 0.49$ & $3.84 *$ & $4.00 *$ & $4.97^{*}$ & $3.98 *$ & - & 12.63 & - \\
\hline $\begin{array}{l}\text { Solids - cresol } \\
\text { insolubles (wt \%) }\end{array}$ & 0.06 & 0.06 & 0.01 & $<0.01$ & $<0.01$ & - & 4.36 & 4.0 \\
\hline Calorific value (Btu/lb) & $16,782 \pm 34$ & $16,871^{*}$ & $16,826 *$ & $16,855^{*}$ & $16,855^{*}$ & 16,700 & 15,958 & 15,815 \\
\hline
\end{tabular}

\footnotetext{
${ }_{\mathrm{FO}}^{\mathrm{F}}=$ filtered oil, $\mathrm{P} \# \mathrm{~B}=$ Pittsburgh \#8 coal-derived oil, I\#6 = Illinois \#6 coal-derived oil.

${ }^{b}$ Storage condition $=$ temperature $\left({ }^{\circ} \mathrm{F}\right)$, followed by gas blanket in vapor space ( $N$ or $A$ for nitrogen or air). All samples are stored in individual 1-pint screw-top steel cans and taken to Analytical Chemistry on alternating months.

$c_{\text {Ultimate analyses are on MAF basis. }}$

$\mathrm{d}_{\text {Standard deviations are } \pm \text { figures. }}$.

*Value exceeds plus or minus two times the standard deviation.
} 


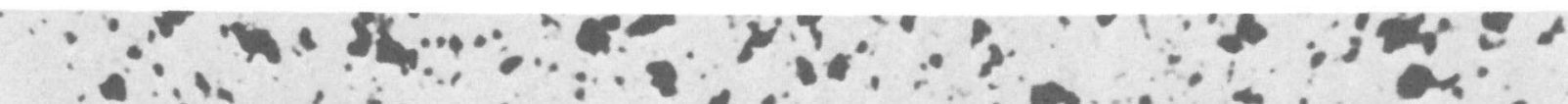
st. $\therefore$ A

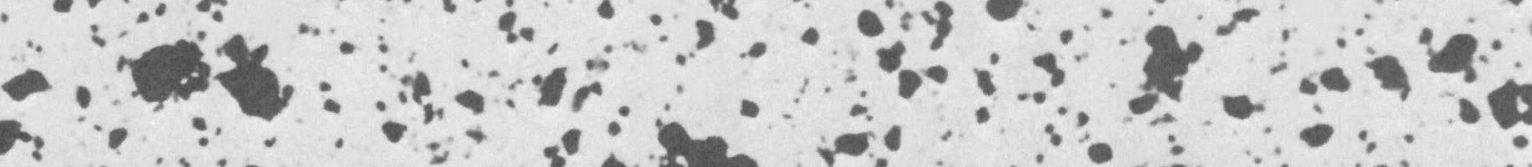

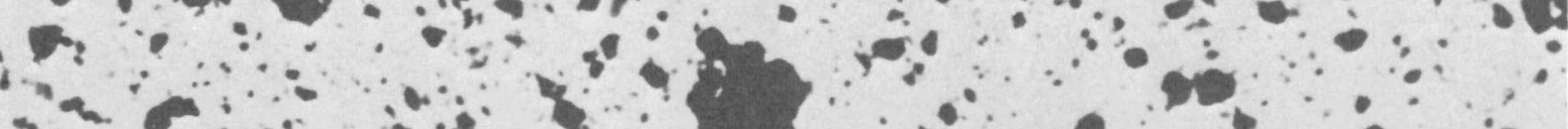
wo

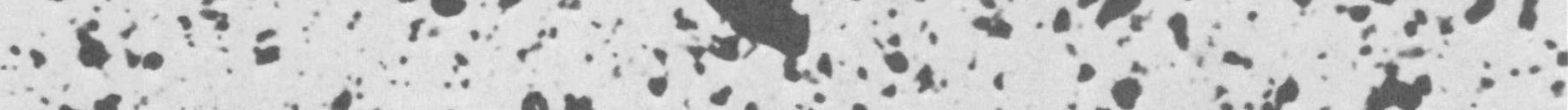
d. $+a^{2}$ 8.

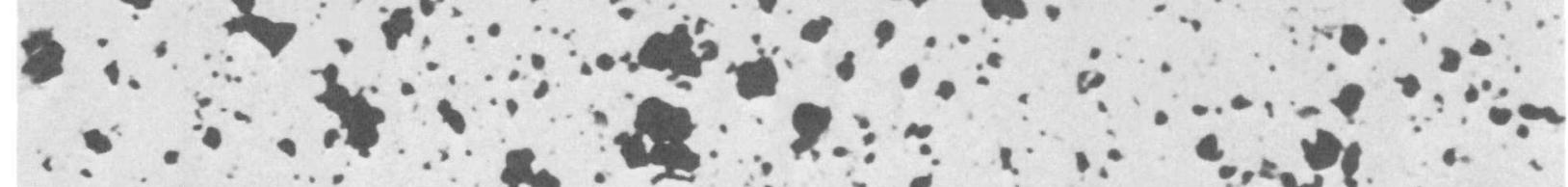

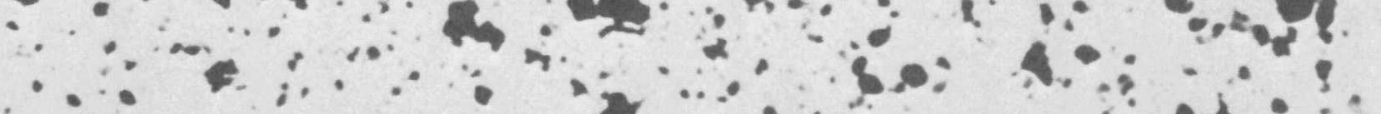

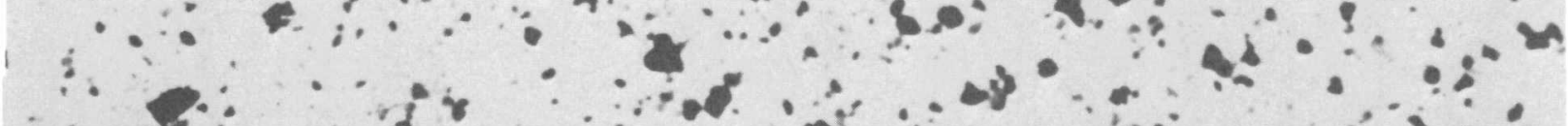

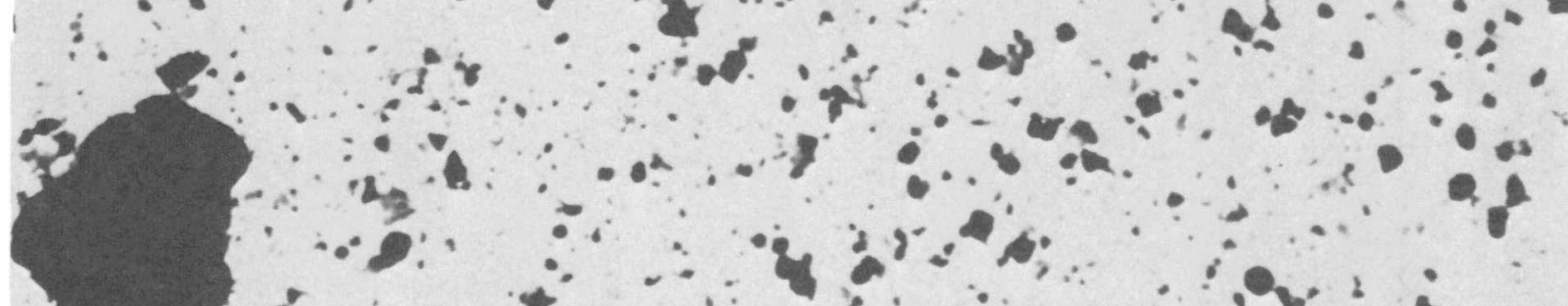

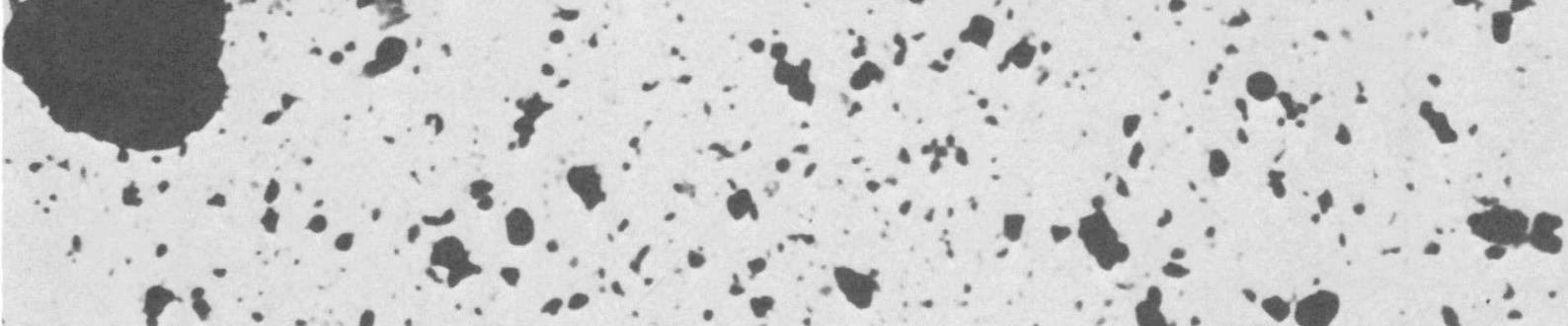
$\therefore$ a $\begin{array}{llll}1 & 1 & 1 & 1 \\ 0 & 2 & 3\end{array}$

Fig. 3.3. Electron micrograph of solids contained in SRC-UFO from Pittsburgh No. 8 coal. 
ORNL-DWG 76-124RI

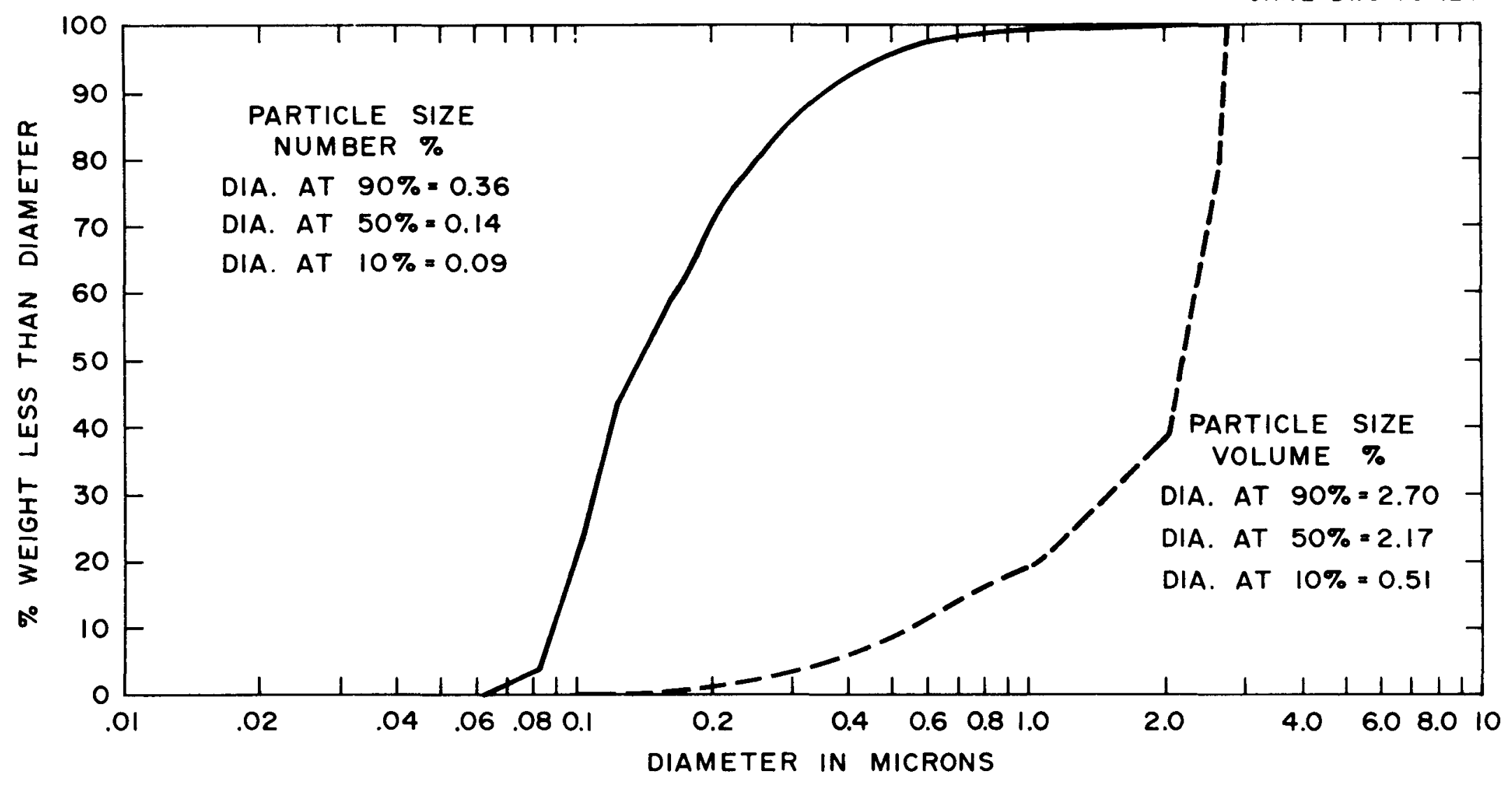

Fig. 3.4. Particle size distribution of SRC-UFO from Pittsburgh

No. 8 coal by electron microscope. 
$0.8 \mu$ appeared to be rough at the edges and may be made up of smallex particles. Small particle bridges between large particles were common in the unheated sample. In contrast, the heated sample contained particles which were highly agglomerated; the particles were smooth, and there were no small particle bridges. These results are consistent with previous results which indicated that restructuring of the particulates occurred with heating. The fact that these materials have undergone a similar heating experience during conversion in the pilot plant suggests that some condition in the temperature and pressure let-down system caused the larger particles and agglomerates to break into smaller particles. Viscosity-Temperature Studies

A reverse flow kinematic viscometer was used to measure the viscosity of filtered and unfiltered SRC oil over the range 100-200\%. Viscosities of 5-15\% toluene in SRC-UFO mixtures were also determined. Figure 3.5 shows considerable differences between the viscosities of filtered and unfiltered oil. Upon the addition of 5\% toluene to SRC-UFO, there is a large reduction in viscosity. The viscosity reduction of filtered oil after toluene addition is much less pronounced, indicating that the effect of toluene on the particles in the UFO is important to the solution viscosity.

Gel Permeation Chromatography

Figure 3.6 shows the molecular size distribution of the "as received" SRC-UFO and FO derived from Pittsburgh \#8 coal. Although the curves were similar in shape, there were some differences between the UFO and FO; the percent of molecules greater than $10 \AA$ was $46.0 \%$ for UFO and $36.9 \%$ for $\mathrm{FO}$, and the small peak maximums were shifted slightly to higher molecular sizes for the UFO. More data will be required to determine if differences between FO and UFO are significant. After two months storage of SRC-FO at $140^{\circ} \mathrm{F}$, the percentage of sizes greater than $10 \AA$ was measured as $38.6 \%$ compared to the above values. This difference after two months storage is believed to be insignificant.

Measurements of Vapor Pressure over Solvent Refined Coal Unfiltered Oil Solutions

For equipment design and safety it is necessary to know the vapor pressures above solvent-UFO mixtures. A simple system using a 2.4-cm-ID by 43.5-cm-high stainless steel tube fitted with a Bourdon pressure gauge was utilized to provide approximate operating data for the bench-scale 


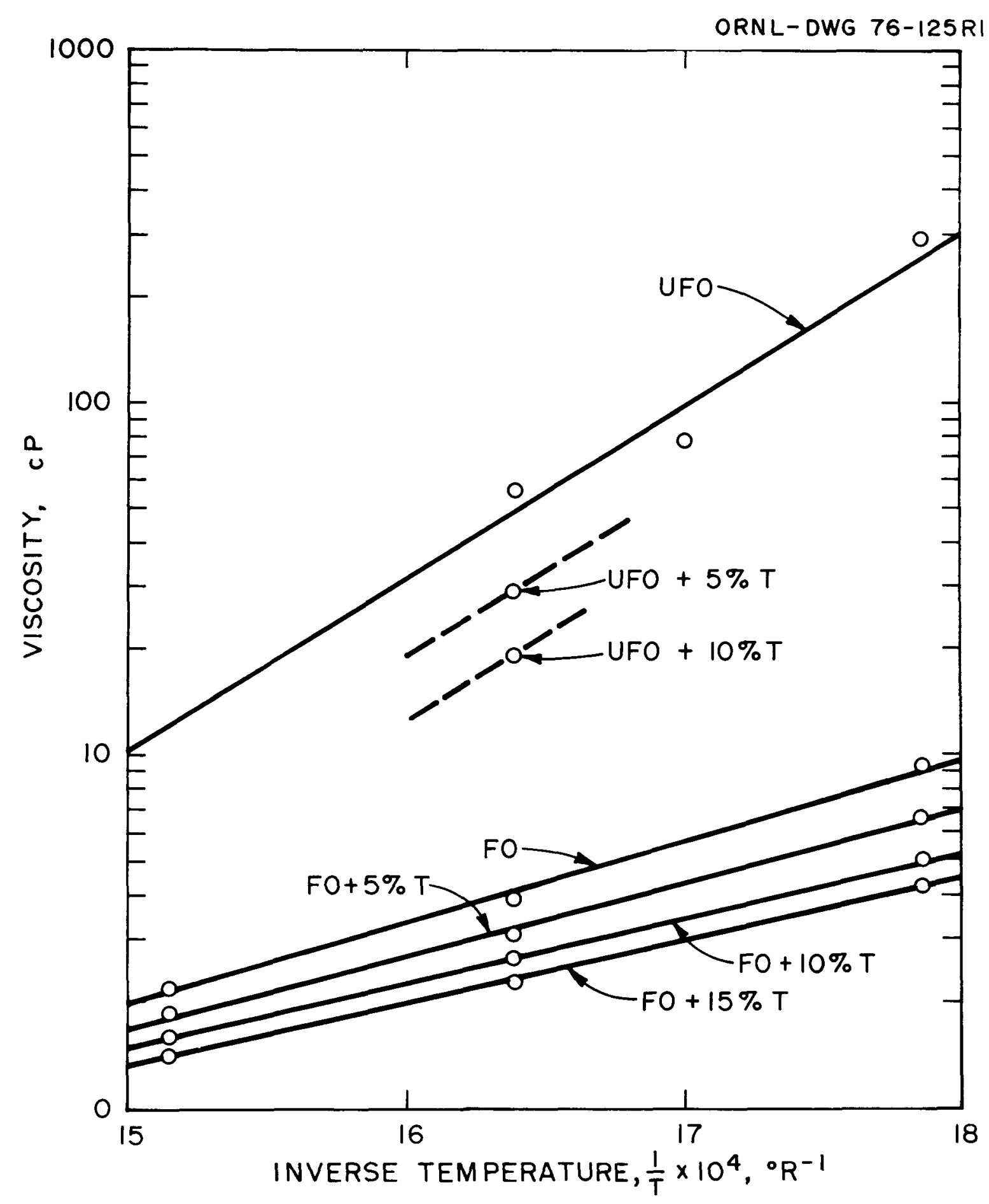

Fig. 3.5. The effect of solvent concentration on SRC oil viscosity. (UFO = unfiltered oil, $\mathrm{FO}=$ filtered oil, $\mathrm{T}=$ toluene.) 


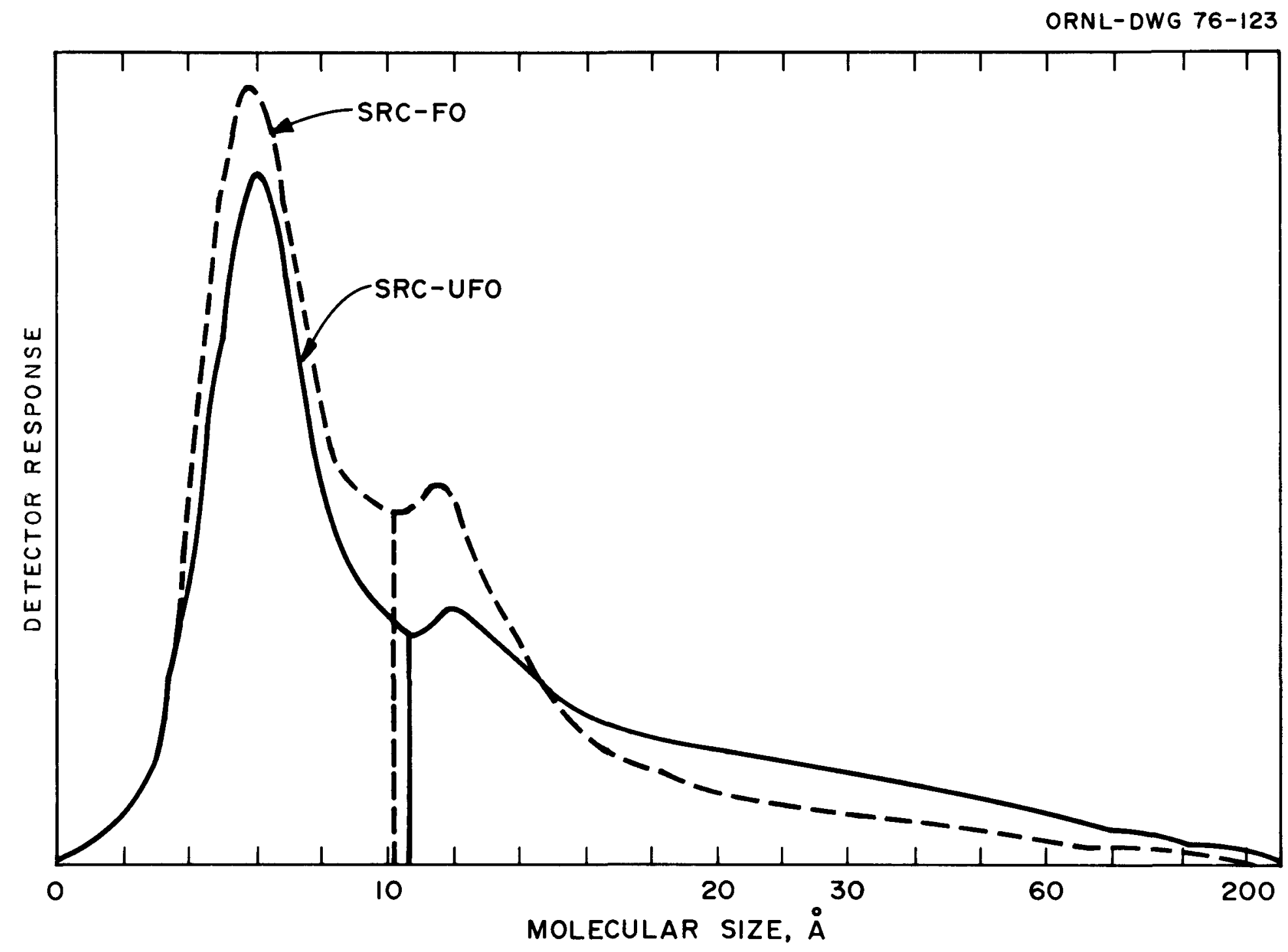

$\omega$

Fig. 3.6. Molecular distribution of SRC oils. 
system. No correction was made for the $20 \mathrm{cc}$ void volume of air at the beginning of each run; the air in the vapor phase would exert about 25 psi at $260^{\circ} \mathrm{C}$. Mixtures weighing $175 \mathrm{~g}$ were sealed in the above tube and immersed in a bath of silicone oil. Initially, the bath temperature was raised at rates of $1-2^{\circ} \mathrm{C}$ per minute. However, heating rates had to be lowered signficantly during the latter part of the run due to large pressure changes with temperature.

Figure 3.7 shows that the pressure over the unfiltered oil at $300^{\circ} \mathrm{C}$ was $45 \mathrm{psig}$. Apparently, changes occurred above $350^{\circ} \mathrm{C}$ wich produced a "hysteresis" effect as the temperature was lowered; $300^{\circ} \mathrm{C}$ during the temperature reduction portion of the cycle gave a total pressure of 100 psig. However, it is possible that longer times were required to reach vapor-liquid equilibrium. Adding toluene to the unfiltered oil increased the tctal pressure in the vapor phase as expected; at $300^{\circ} \mathrm{C}$ and $9 \%$ toluene the pressure was $135 \mathrm{psi}$, and the $20 \%$ toluene mixture produced a pressure greater than 200 psig at $260^{\circ} \mathrm{C}$. There was no hysteresis effect for the latter two mixtures, possibly due to the fact that the temperature never exceeded $300^{\circ} \mathrm{C}$.

Spectrochemical Analyses of Two Coal Feeds to the SRC Plant at Wilsonville, Alabama

Table 3.7 gives the results of excitation spectrochemical analyses comparing Illinois \#6 coal to Pittsburgh \#8 coal. Although some differences are noted, the elemental contents of both samples are similar.

\subsection{References for sect. 3}

1. J. P. Nichols (Program Director), Coal Technology Program Quarterly Progress Report for the Period Ending September 30, 1975, ORNL 5093 (December 1975).

2. J. P. Nichols (Program Director), Coal Technology Program Progress Report for November 1975, ORNL-TM-5214 (January 1976).

3. $\bar{B} \cdot$ R. Rodgers and S. Katz, Suppurting Research and Development on Separations Technology: Phase II Report, ORNL-TM-4968 (October 1975). 


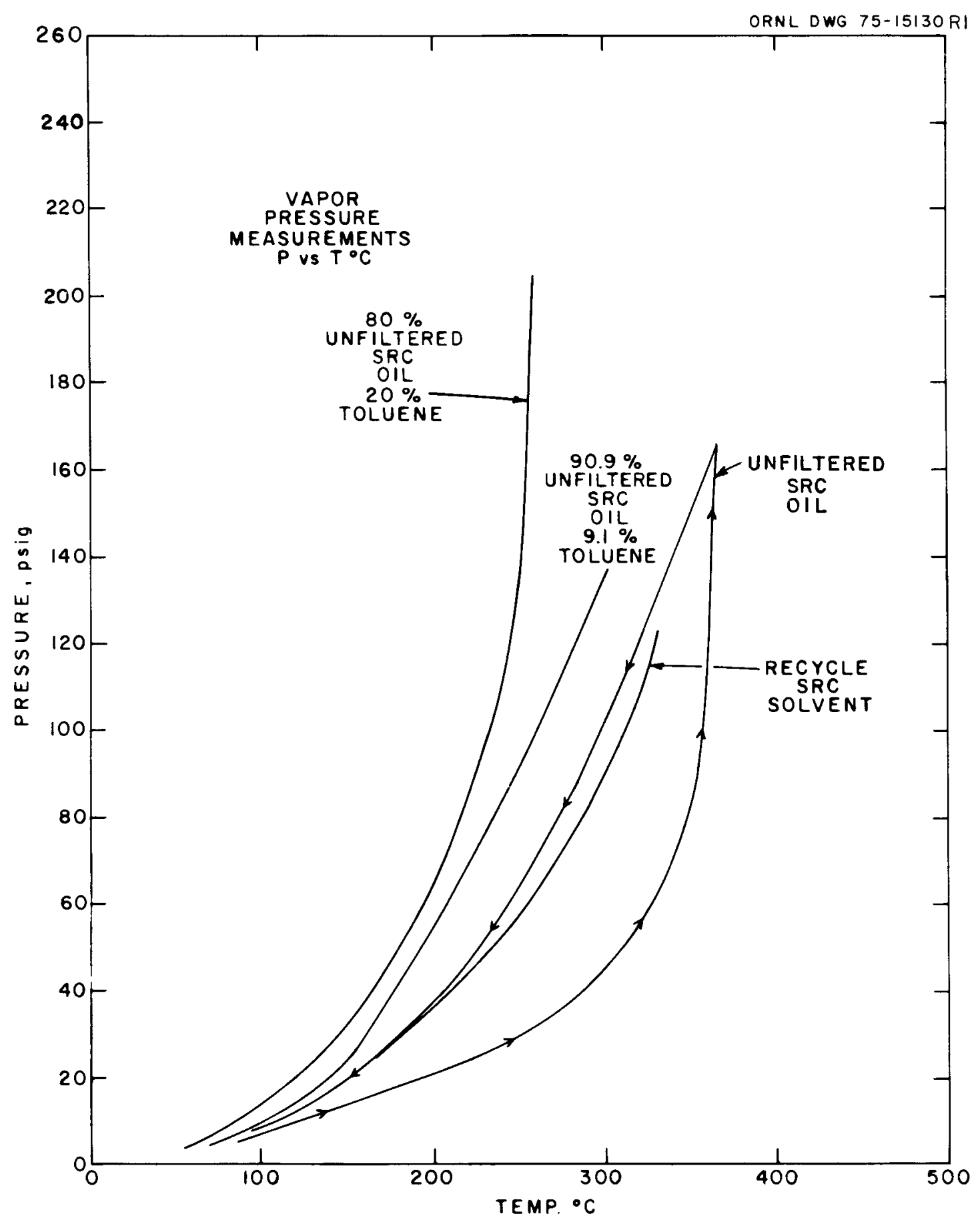

Fig. 3.7. Total pressure during warm-up of laboratory apparatus. 
Table 3.7. Spectrochemical analyses of two coal feeds to the Wilsonville, Ala. SRC plant. Values are in parts per million

\begin{tabular}{|c|c|c|c|c|c|}
\hline & $\begin{array}{c}\text { Illinois } \\
\# 6\end{array}$ & $\begin{array}{c}\text { Pittsburgh } \\
\# 8\end{array}$ & & $\begin{array}{c}\text { Illinois } \\
\# 6\end{array}$ & $\begin{array}{c}\text { Pittsburgh } \\
\frac{\| 8}{\pi}\end{array}$ \\
\hline$A I$ & 5000 & 5000 & $M n$ & 75 & 50 \\
\hline As & 5 & 7 & Mo & 7 & 3 \\
\hline B & 400 & 200 & $\mathrm{Na}$ & 400 & 300 \\
\hline $\mathrm{Ba}$ & 50 & 100 & $N b$ & 1 & 2 \\
\hline $\mathrm{Be}$ & 1 & 0.5 & $\mathrm{Ni}$ & 20 & 20 \\
\hline $\mathrm{Bi}$ & 5 & 3 & $\mathrm{P}$ & 50 & 100 \\
\hline $\mathrm{Ca}$ & $>10,000$ & $>10,000$ & $\mathrm{~Pb}$ & 30 & 10 \\
\hline $\mathrm{Cd}$ & 2 & 1 & $\mathrm{Rb}$ & 50 & 50 \\
\hline Co & 1 & 3 & $\mathrm{Sc}$ & 0.5 & 0.5 \\
\hline $\mathrm{Cr}$ & 30 & 30 & $\mathrm{Si}$ & $>10,000$ & $>10,000$ \\
\hline $\mathrm{Cs}$ & 3 & 3 & Sr & 50 & 100 \\
\hline $\mathrm{Cu}$ & 10 & 7 & Th & 2 & 2 \\
\hline $\mathrm{Fe}$ & 10,000 & 10,000 & $\mathrm{~T} \mathbf{i}$ & 1300 & 1500 \\
\hline $\mathrm{Ga}$ & 2 & 5 & U & 3 & 2 \\
\hline $\mathrm{Ge}$ & 7 & 5 & V & 100 & 50 \\
\hline$F$ & 20 & 30 & W & 3 & 1 \\
\hline $\mathrm{K}$ & 1000 & 500 & $\mathrm{Zn}$ & 400 & 300 \\
\hline Li & 50 & 20 & $\mathrm{Zr}$ & 20 & 20 \\
\hline $\mathrm{Mg}$ & 700 & 1000 & & & \\
\hline
\end{tabular}


4. CHEMICAL RESEARCH AND DEVELOPMENT

$$
\text { G. P. Smith }
$$

The first of the following three reports describes research on several aspects of the physical structure of coal, namely: the application of transmission electron microscopy and small-angle $\mathrm{x}$-ray scattering to a study of the pore structure in coal, and petrographic analyses of solids filtered from the product material of the COED process. The second report describes studies of the sorption and desorption of water vapor on a cobalt-moly catalyst, while the last report describes research on the catalytic chemistry of the same catalyst.

\subsection{Physical Structure of Coal}

L. A. Harris, R. W. Hendricks, and C. S. Yust

Research on coal structure by means of transmission electron microscopy gave the following results. The porosity of the exinite and inertinite constituents of a high volatile bituminous coal was observed to fall mainly in the mesopore size range (20 to $500 \AA$ in diameter). Small particles (about $250 \AA$ in diameter) were seen in a majority of the exinite pores and are believed to have acted as catalysts in the pore formation. Submicroscopic minerals such as kaolinite and quartz were identified by electron diffraction and shown to be intimately associated with the matrix coal constituents.

Small-angle x-ray scattering experiments have been carried out on two specimens of a high volatile bituminous coal. Both samples were originally examined by optical microscopy and high-angle x-ray diffraction in order to determine the amount, size, and type of minerals within these samples. A minimal amount of mineral matter was observed, suggesting that the low-angle $x$-ray scattering curve could be interpreted on the basis of pore distribution.

Coal petrographic analyses have been made on additional samples of filtered solids from the COED-UFO. Pyrite particles below I- $\mu$ m size are 
abundant and a size distribution analysis is planned for this material using a scanning electron microscope interfaced to an image analyzer system.

This research was supported in part by the Fossil Energy Division and in part by the Division of Physical Research of the Energy Research and Development Administration.

\subsection{Properties of Catalyst Surfaces \\ E. L. Fuller, Jr. and P. A. Agron}

The rates of reactions with heterogeneous catalysts depend upon the accessibility to reactive sites. We have studied the surface properties of a cobalt oxide-molybdenum oxide catalyst (Harshaw CM-401P) in the tableted (1/8-in. right cylinders) form. Three of these pellets were placed in a microgravimetric system (ca $107.7 \mathrm{mg}$ ) and evacuated at $22^{\circ} \mathrm{C}$ ( $102.3 \mathrm{mg}$ at $10^{-7}$ torr). Thence a nitrogen isotherm $\left(-196^{\circ} \mathrm{C}\right)$ was measured as shown in Fig. 4.1. The outgassing temperature was increased incrementally to $400^{\circ} \mathrm{C}$ (ca $97.5 \mathrm{mg}$ ) with steady-state weights achieved in 4 to 6 hours at $10^{-7}$ torr (and verified by monitoring for 16 to $96 \mathrm{hr}$ at the respective temperatures). Figure 4.2 is a presentation of the specific surface area calculated by the BET method and using the vacuum weight at $1000^{\circ} \mathrm{C}$ ( ca $95.1 \mathrm{mg}$ ) as the weight of catalyst. Also shown in Fig. 4.2 is the vendor's quoted $160 \mathrm{~m}^{2} / \mathrm{g}$ for outgassing at 180 to $190^{\circ} \mathrm{C}$. Apparently they utilized the atmospheric weight of sample as their normalizing factor. Good agreement with our results is obtained if we adjust their value in proportion to our observed weight loss on evacuation and heating at $1000^{\circ} \mathrm{C}$.

The increase in specific surface is quite pronounced as more and more bound species $\left(>95 \% \mathrm{H}_{2} \mathrm{O}\right)$ aredriven off at higher temperatures. No appreciable sintering is observed for temperatures less than $400^{\circ} \mathrm{C}$. The sample was returned to $22^{\circ} \mathrm{C}$ (after the $400^{\circ} \mathrm{C}$ outgas) and exposed to water vapor at saturation vapor pressure during the course of construction of the water vapor isotherm. The vacuum weight (ca $102.3 \mathrm{mg}, 22^{\circ} \mathrm{C}$ ) increased 


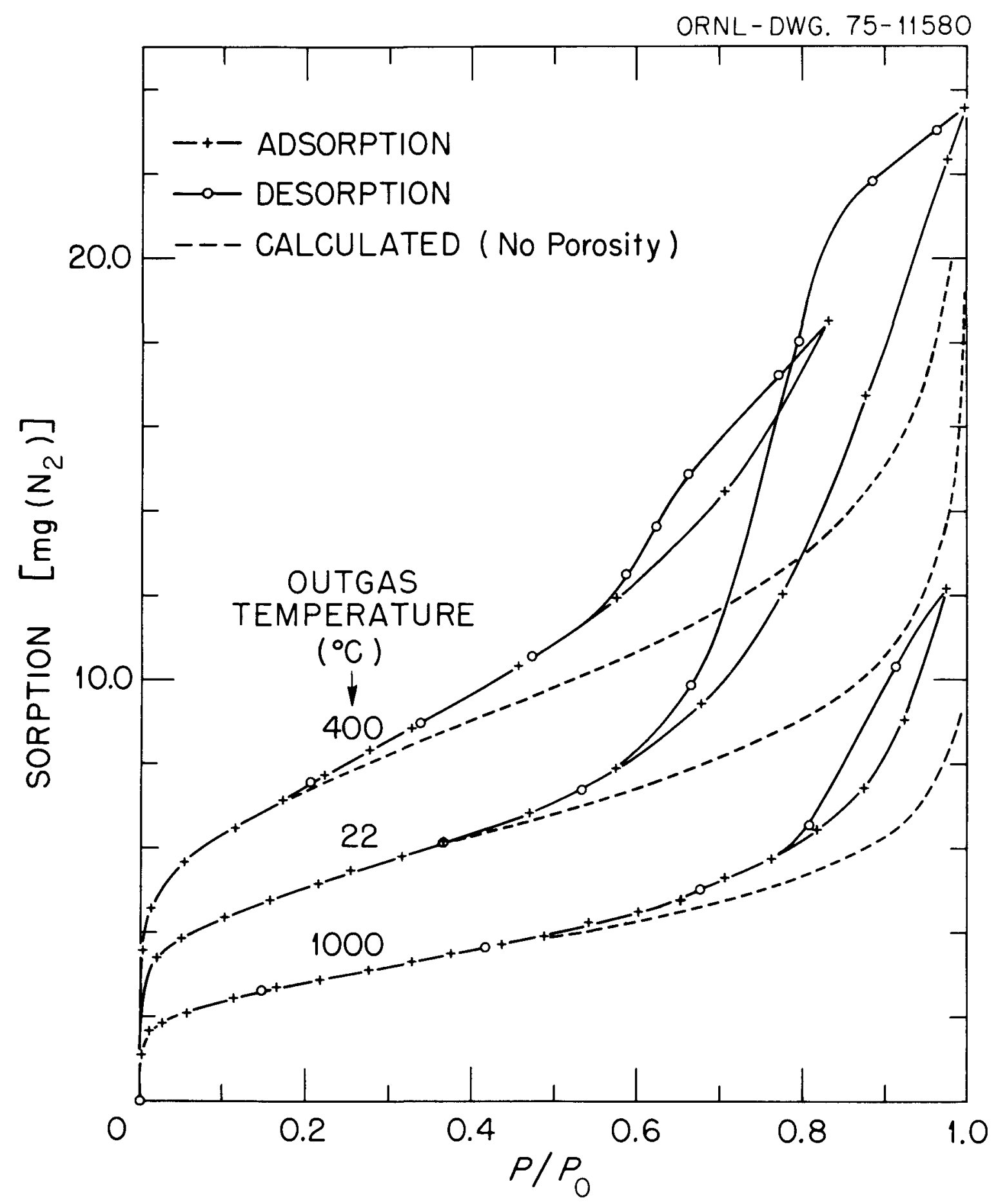

Fig. 4.1. Nitrogen sorption on CM3 at $77^{\circ} \mathrm{K}$. 


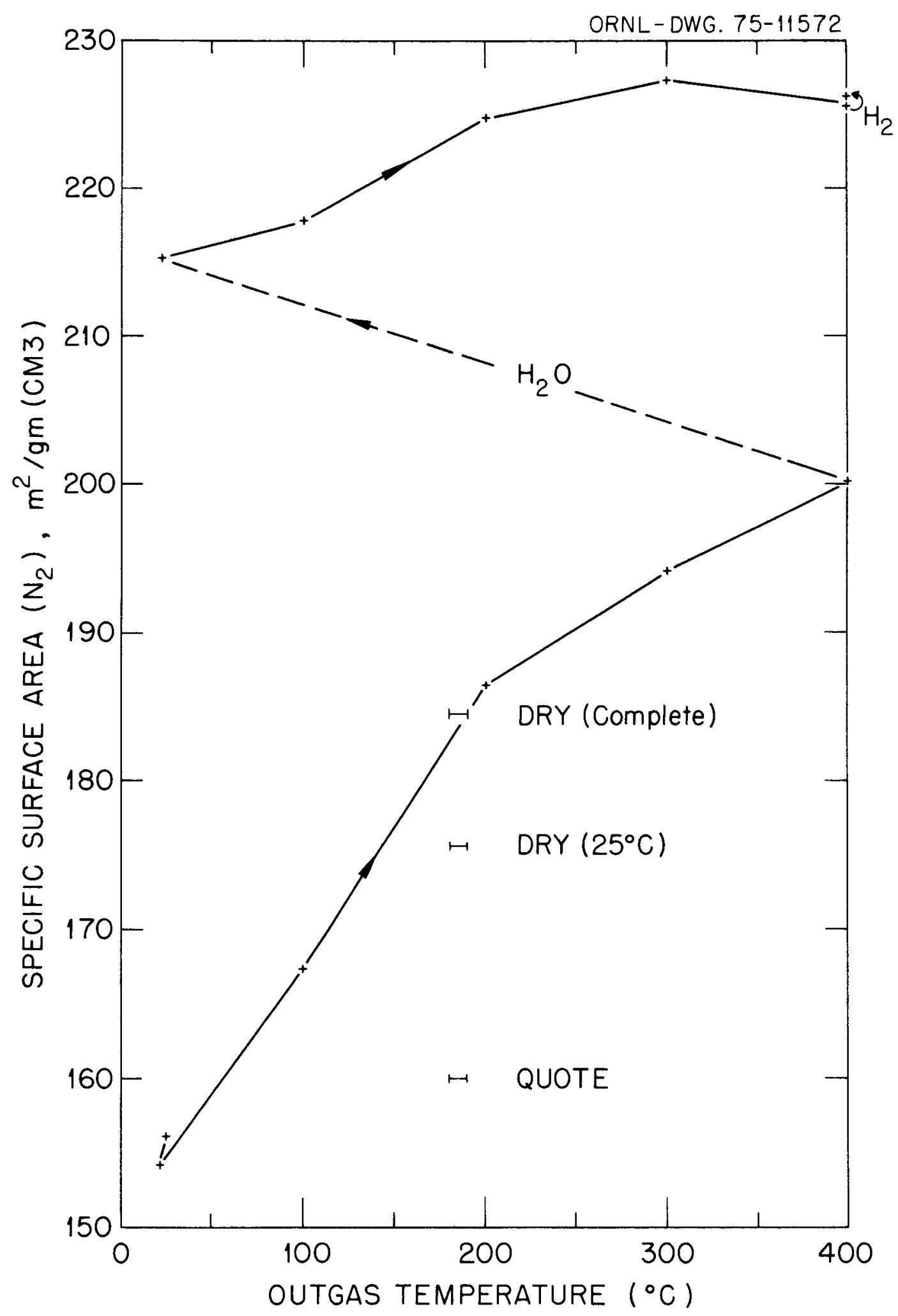

Fig. 4.2. Specific surface area of CM3. 
as the original bound complement was readsorbed irreversibly. Repetition of the previous thermodesorption (outgassing) sequence gave approximately the same weight loss results. However a marked increase in the apparent specific surface area was induced and maintained as noted in Fig. 4.2.

It seems that exposure to high relative humidity $(\geq 75 \%)$ leads to capillary condensation of water and irreversible modification of the structure of the pelletized catalyst. This may be due to relief of interparticulate strains and/or reaction with any residual binder that may remain from the original fabrication processes.

These results show the marked dependence of the nature of the catalyst on treatment temperature and other "past history" effects. Further work is underway to evaluate surface properties with the goal of optimizing and/or improving catalyst performance.

This research was supported by the Division of Physical Research of the Energy Research and Development Administration.

\subsection{Chemistry of Heteroatom Removal from Coal \\ P. A. Agron and R. A. Strehlow}

The catalytic removal of heteroatoms has continued to be the method studied so far in this program. Evaluation of a sulfided form of a cobalt molybdate catalyst has been made for several reactions that model some of the processes which occur in catalytic coal liquefaction. The processes which occur include:

1. Hydrodesulfurization

2. Hydrodenitrogenation

3. Hydrogen addition

4. Hydrocarbon reformation and hydrocracking

5. Hydrodeoxygenation

The first of these was studied in this work using as model reactions the reactions of hydrogen with thiophene, 2-methylthiophene, and 2,5dimethylthiophene. These are not ideal models for the sulfur species in coal, but served to normalize our experimental approach. The data 
are being analyzed. Basically, the rates of reaction of the methylated thiophenes were not greatly different from those of thiophene itself. We found a significant variation of hydrocarbon yield, depending on the $\mathrm{H}_{2} \mathrm{~S} / \mathrm{H}_{2}$ pressure ratio. This phenomenon is being studied in an effort to develop methods for counting active sites on the catalyst. A titration technique will be employed using a gas chromatographic system which is now being adapted for this purpose.

Hydrodenitrogenation has been initially examined using pyridine and pyrrole, which have the effect of blocking some varieties of sites on the catalyst as well as being denitrogenated. This is important in the reaction network analysis. An objective in this catalytic work is to assess the varieties of sites and determine their various functions in coal liquefaction. Deuterium has been used with both the sulfur and the nitrogen compounds in this work. The results of these studies are shown in Table 4.1, along with some reactions with protium in Table 4.2. The cobalt molybdate catalyst was more active for hydrodesulfurization than for denitrogenation. As seen in the table, the ease of hydrogen replacement was greater than that for desulfurization. Flow and pressure regimes were found where thiophene was almost completely deuterated with no desulfurization occurring.

If hydrogen addition (hydrogenation) occurs at all with the heterocyclic compounds we have studied, the reaction is sufficiently slower than the further reactions involving heteroatom removal so that it is difficult to determine whether the hydrogenolysis occurs with or without prior ring saturation. The presence of butenes in large amounts as products from thiophene indicates that ring saturation is not necessary. Studies with butadiene hydrogenation were conducted and support this conclusion, which also agrees with work described in the literature.

So far in this work we have not explored any possible model reactions for reforming, hydrocracking, or hydrodeoxygenation. All of these are expected to be significant in heteroatom removal during coal treatment. Work is continuing on developing a method for determining the active site concentration on cobalt-molybdate catalysts using a sulfur compound 
titrant. Work is also progressing on a high-temperature injection system to facilitate studies of hydrogenolysis of model compounds with low vapor pressures.

Table 4.1. Summary of deuterium reactions studied

Temperature: $425^{\circ}$ except where noted

$\mathrm{P}_{\mathrm{H}_{2} \mathrm{~S}} / \mathrm{P}_{\mathrm{H}_{2}}$ : $\sim 5 \times 10^{-4}$ (with transients due to $\mathrm{H}_{2} \mathrm{~S}$ produced)

Pressures:

$\mathrm{D}_{2} \sim 200 \mathrm{KPa}$ (2 atm)

Organic reactant: $\sim 5-15 \mathrm{~K} \mathrm{~Pa}(0.05-0.15 \mathrm{~atm})$

\begin{tabular}{|c|c|c|}
\hline Reaction $^{\mathrm{a}}$ & WHSV $\left(h r^{-1}\right)^{b}$ & $\begin{array}{c}\text { Approximate } \\
\text { Conversion } \\
(\%)\end{array}$ \\
\hline Benzene $+\mathrm{D}_{2} \rightarrow$ Benzene- $\mathrm{d}_{1-6}$ & 1.5 & 100 \\
\hline Pyridine $+D_{2} \rightarrow$ Pyridine- $d_{1-5}$ & 1.7 & 90 \\
\hline$\rightarrow$ Pentanes, Pentenes & 1.7 & 10 \\
\hline$\rightarrow$ Pentanes, Pentenes & 0.4 & 30 \\
\hline$\rightarrow$ Piperidine & 1.7 & 0 \\
\hline Pyrrole $+\mathrm{D}_{2} \rightarrow$ Pyrrolidine & 1.7 & 0 \\
\hline$\rightarrow$ Pyrrole- $a_{1-5}$ & 1.7 & 80 \\
\hline$\rightarrow$ Pyrrole- $\mathrm{d}_{1-5}\left(325^{\circ} \mathrm{C}\right)$ & 1.7 & $<50$ \\
\hline$\rightarrow$ Butanes, Butenes & 1.7 & $<30$ \\
\hline Thiophene $+D_{2} \rightarrow$ Butanes, Butenes & 0.5 & 100 \\
\hline$\rightarrow$ Butanes, Butenes & 1.8 & 80 \\
\hline$\rightarrow$ Butanes, Butenes & $3 \cdot 5$ & 20 \\
\hline$\rightarrow$ Thiophene- $\mathrm{a}_{1-4}$ & 3.5 & 80 \\
\hline
\end{tabular}


Table 4.2. Reactions of thiophene

(Conditions as for Table 4.I)

\begin{tabular}{ccc}
\hline Reaction & $\begin{array}{c}\text { WHSV } \\
\left(\mathrm{hr}^{-1}\right)\end{array}$ & $\begin{array}{c}\text { Approximate } \\
\text { Conversion } \\
(\%)\end{array}$ \\
\hline Thiophene $+\mathrm{H}_{2} \rightarrow$ Butanes, Butenes & 1.8 & 80 \\
2-Methylthiophene $+\mathrm{H}_{2} \rightarrow$ Pentanes, Pentenes & 1.8 & 70 \\
2,5-Dimethylthiophene & 1.8 & 70 \\
\hline
\end{tabular}




\section{ANALYTICAL CHEMISTRY}

W. D. Shults

Separation and chemical characterization of coal-derived products are carried out within the Analytical Chemistry Division. These projects are supported by ERDA and NSF/RANN and include several studies related to health and environmental problems which are carried out jointly with other divisions participating in the Ecology and Analysis of Trace Contaminants Program (R. I. Van Hook, Principal Investigator).

\subsection{Analytical Research and Development}

M. R. Guerin

$\underline{\text { Summary }}$

Synthoil and COED process oil samples have been chemically fractionated for biological and chemical characterization. Isomeric methyl chrysenes have been identified in synthoil. Developmental work has continued toward achieving cleaner fractionation of chemical classes than has previously been afforded by the more conventional schemes. Studies to characterize aqueous effluents from the Synthane process and in-situ shale oil retorting have commenced.

Chemical fractionation and characterization of coal-derived materials (W. H. Griest, C. H. Ho, A. R. Jones, I. B. Rubin, and A. D. Horton)

The separation of complex mixtures into chemical classes is a necessary precedent to biological and chemical characterization of fractions. While the stedman separation scheme has been used rather routinely in providing samples to date, other methods are being explored and compared to determine the distributions of various specific compounds across the resultant fractions.

The API-60 chromatographic procedure commonly applied to petroleum products suffers from serious limitations relative to the production of fractions for biological testing. Among the problems encountered are artifact formation and uncertain distributions of certain compound classes 
across the fractions obtained. These observations are credited to members of the Laramie Energy Research Center. We are presently setting up equipment to investigate the use of gel permeation chromatography for molecular size fractionation as an ancillary technique to other methods. Some basic studies have been carried out with conventional liquid-liquid extractions using polar/nonpolar organic solvents rather than pH-based extractions which are liable to produce artifact formation. Using this extraction method, stearic acid and phenol were recovered essentially quantitatively (98\%) in methanol during methanol/cyclohexane extraction provided cyclohexane backwashing was omitted.

A Synthoil sample was separated into Stedman class fractions and delivered to the Pittsburgh Energy Research Center for GC-MS analyses. Data from these analyses should give some indication of the efficacy of the stedman procedure for yielding good separations on this coal-derived Iiquid.

Isomeric methyl chrysenes have been tentatively identified in synthoil. Analysis of the purified alkyl-chrysene fraction gave quantitative estimations as follows: chrysene (98 ppm), 2-methyl chrysene (102 ppm), 3-methyl chrysene (106 ppm), and 6-methyl chrysene (64 ppm). Significantly, 5-methyl chrysene, a strong carcinogen, was not detected in the synthoil s ample.

Developmental work on GLC capillary columns has continued in order to perform analyses with increased resolution. Coating of glass columns with a uniform film of liquid phase has been achieved with OV-1Ol. A methylene chloride solution of 10\% OV-101--0.2\% tetraphenylphosphonium chloride (TPPC) was used to coat a 161-ft $\times 0.26-\mathrm{mm}-\mathrm{ID}$ column at the rate of $0.25 \mathrm{~cm} / \mathrm{sec}$. Chromatographic profiles of PAHs from coal-derived liquids showed excellent resolution of isomers amenable to separation by $0 \mathrm{~V}-101$.

Analyses of aqueous effluents from fossil fuel technologies (B. R. Clark, M. R. Guerin, C. H. Ho, and I. B. Rubin)

Since the aqueous products or process streams from fossil fuel conversion technologies have a large potential for entering the environment, a substantial effort has commenced to biologically and chemically 
characterize these aqueous mixtures. Collaborative efforts have been established with the Laramie Energy Research Center (LERC) in the analyses of shale oil-related waters and with the Pittsburgh Energy Research Center (PERC) in the analyses of Synthoil and synthane related waters. Current developmental efforts include: separation of shale oil from its oil-water samples, the extraction and concentration of dissolved and suspended organic compounds, and the identification of major constituents in the various waters. Whole samples are concurrently being tested for biological activity by J. L. Epler of the Biology Division, and acute toxicity studies are being conducted by C. W. Gehrs and S. Herbes of the Environmental Sciences Division. The methodology being developed within the framework of multidivisional collaboration should result in a unique capability for biological-chemical characterization of these very important aqueous effluents.

\subsection{Analytical Services \\ W. R. Laing}

A total of 390 samples were submitted for analysis during this quarter.

A rotary evaporator was delivered and has been put into use in the low-temperature evaporation of solvents used in solvent fractionation of soluble coal-derived liquid products. By evaporation of the solvent at temperatures under $30^{\circ} \mathrm{C}$, thermal decomposition of the product is minimized, thus making it possible to recover the separate fractions for further characterization tests.

ASTM Method D2887, Boiling Range Distribution of Petroleum Fractions, has been set up on the Tracor 222 gas chromatograph using a 6-ft by 1/4-in. Dexsil 300 column. A calibration curve was prepared from standards with boiling points in the range from 150 to $372^{\circ} \mathrm{C}$. Samples of SRC liquid product were tested.

A gas sampling manifold, a manometer, and a sampling loop were installed on the Tracor 222 chromatograph. A marked reduction in downtime, as compared to that experienced with the use of the Varian chromatograph on a part-time basis, has resulted from this change. 
The water content of tar samples produced during hydrocarbonization tests was determined by distilling the xylene-water azeotropic mixture from 10 - to 20-g samples and collecting and measuring the water in a Dean Stark water trap. The water content of samples tested ranged from 15 to 35\%. By applying this method and using large samples, the results are more representative of the entire batch of tar collected during the run.

Proximate and ultimate analyses of coals and chars derived from hydrocarbonization tests, and ash determinations on a large number of samples derived from solid-liquid separation tests continued on a routine basis. 


\section{ENGINEERING EVALUATIONS OF THE HYDROCARBONIZATION AND SYNTHOIL PROCESSES}

J. M. Holmes, R. Salmon, and E. G. St. Clair

$\underline{\text { Summary }}$

Synthoil. Capital, utility, and chemical make-up costs for the potassium carbonate scrubbing units were received from the Benfield Corporation. The Pennwalt Corporation provided all available data on the testing of Synthoil liquids in Sharples centrifuges at about $200^{\circ} \mathrm{F}$. The Johns-Manville Company supplied a conceptual design of a rotary drum precoat filter specifically designed for coal-derived liquids. Conceptual design of the solids-liquid separation plant was completed. Equipment sizing and costing are underway. Process flow diagrams for four units (the two co shift units and two acid gas removal units) were finalized, along with heat and material balances and equipment lists. Preliminary process flow diagrams were completed for the gasification and low-temperature carbonization units. A preliminary synthoil facility site plan was developed. An analysis of the design, fabrication, and operation of the Synthoil unit reactor vessels was initiated. The completed analysis will treat hot-wall vessels and refractory-lined vessels with regard to materials of construction, code requirements, fabrication techniques, vendor capabilities, and costs.

Hydrocarbonization. In the hydrocarbonization work, the overall flow diagram and material balance were firmed based upon estimated yields from U.S. Steel's "Clean Coke" process. Material balances for various units are under preparation and equipment sizing and cost estimating is underway. Cost estimates for the major items are currently being developed by a number of equipment manufacturers. McNally-Pittsburg Manufacturing Company is completing a subcontract for the beneficiation system, and a design criteria has been prepared for a subcontract to Fluidized Bed Combustion Company (FBCC) for the fluidized bed combustor. Based upon interim results, a hydrocarbonization system will be recommended for evaluation as a scaled-down demonstration plant. 


\subsection{Synthoil Process}

R. Salmon, M. S. Edwards, D. E. Reagan, E. G. St. Clair, and W. C. Ulrich

Compressor and driver selections and cost estimates for the recycle gas compressor, the CO shift feed gas compressor, and the hydrogen make-up gas compressor were received from Elliott Company. Agreement was reached with Pacific Pumps to help us with pump and driver selections and cost estimates. Process requirements for the sulfur plant were sent to the R. M. Parsons Company, and they agreed to provide a sulfur plant design and cost estimate.

A computer program was completed for calculating and tabulating the overall block flow material balance. The material balance calculated by this program was incorporated into the overall flow diagram. A FORTRAN program was written for the heat and material balance calculations of the high-temperature CO shift unit. The results agree well with those of the Girdler program. The flow diagram is being completed based on the results of these programs. A Lawrence Livermore Laboratory computer program for multicomponent fractionation was tested successfully. It was then used to check the Synthoil recycle gas methane absorber. The results agreed well with those of our own calculations.

The PDA (Process Design Analysis) computer code of McDonnell-Douglas Automation Company was used to determine coefficients of a cubic equation for the effect of temperature on the enthalpy of a number of compounds and petroleum fractions at four pressures (2, 800, 1600, and 2499 psia) for use in heat balance calculations. The coefficients were determined for the compounds and petroleum fractions for both the gaseous and liquid states (i.e., there are eight coefficients for each compound or petroleum fraction). A subroutine was then written to calculate the enthalpy of a given compound at a specific temperature and pressure for use in heat duty calculations. The subroutine calculates the enthalpy at the temperature for all four pressures and then uses the Lagrangian interpolation method to determine the enthalpy at the desired pressure. 
Computer codes (previously written) to calculate heat and material balances for the CO shift units were augmented with new data supplied by Girdler Catalysts, Incorporated, using cobalt molybdate catalyst. Computer codes were also written to calculate heat and material balances for the hot carbonate and DEA gas treating processes.

Process flow diagrams were finalized, and heat and material balances and equipment lists were developed for the following units:

$\begin{array}{ll}\text { Unit } 14 & \text { High Temperature CO Shift } \\ \text { Unit 20 } & \text { Low Temperature CO Shift } \\ \text { Unit } 19 & \text { Raw Gas Treating } \\ \text { Unit } 21 & \text { Shifted Gas Final } \mathrm{CO}_{2} \text { Removal }\end{array}$

The various sections of the Synthoil flowsheet progressed as follows:

(1) Equipment selection and plant layouts: The Synthoil filter gas recycle compressors were sized and selected. The data sheets and associated material balances for the high-temperature co shift unit reactor effluent cooler, 50-psig steam generator, and shifted gas cooler were forwarded to Nooter Corporation for rating and pricing information. A preliminary overall Synthoil facility site plan was developed.

(2) Synthoil reactor vessel: As presently conceived, the Synthoil unit will require 36 reactor vessels, each with an 8-ft, 4-in. internal diameter and a 14-ft, 6-in. catalyst bed depth. Process conditions dictate that the reactor vessel be designed to operate at approximately 4250 psig and $860^{\circ} \mathrm{F}$ and to resist attack by high partial pressures of hydrogen and the corrosive effects of hydrogen sulfide. An analysis of the design, fabrication, and operation of the reactor vessels is currently underway. The completed analysis will treat hot-wall vessels and refractory-lined vessels (both with alloy liners) with regard to materials of construction, code requirements, fabrication techniques, vendor capabilities, and costs. The intent of the brief analysis is not to provide a detailed design, but rather to survey the problems involved, develop an acceptable solution, and provide a cost estimate for use in determining the overall Synthoil unit capital investment. 
(3) Coal handling and preparation: TVA's Paradise Steam Plant and the adjacent Peabody Sinclair coal mine were visited to obtain information on the coal handling, mining capabilities, and overall site layout of this mine-mouth facility. The Paradise operation was discussed with the plant manager, and a tour of the plant was provided. A tour of the Peabody strip mines in the area was also taken.

The flowsheet and the layout plan for the Synthoil coal preparation facility were revised. It was discovered that the 2000 -ton/hr Bradford breakers are only in the planning stage, so a change was made to use the available 1000-ton/hr machines. Also, the pulverizer-dryer layout was revised based upon information obtained from Combustion Engineering Corporation. Equipment lists for the Synthoil coal preparation system are being prepared, and cost information on this equipment is being obtained from vendors. Combustion Engineering Corporation agreed to provide an equipment layout and cost information for the pulverizers, dryers, and auxiliary equipment.

(4) Gasification: The preliminary process flow diagram for the gasification unit was completed, and a computer program was developed for calculating the $r$ aw gas production and composition for various combinations of coal and char feed rates to the gasifier. Equipment lists were tabulated, and a preliminary plot plan of the unit was prepared.

(5) Carbonization: The preliminary process flow diagram for the low-temperature carbonization unit was completed. Based on information reported on the pilot-plant development of the CSF process conducted at Cresap, West Virginia, a computer program for calculating the flowsheet material and heat balances was completed. Work was started on sizing and tabulating the equipment needed for the unit, and a preliminary plot plan of the unit was prepared.

Contact was made with a representative of the Robinson and Robinson Division of the NUS Corporation who was involved in the design, operation, and analysis of the carbonizer at the CSF pilot plant in Cresap. A contract was negotiated for obtaining the assistance of this representative, on a consulting basis, in designing a carbonizer unit for the synthoil facility evaluation. 
(6) Gas treatment: Design of the acid-gas separation plant required in Synthoil was initiated, based on information obtained from the Benfield Corporation on their modified $\mathrm{K}_{2} \mathrm{CO}_{3}$ process. The Benfield Corporation also provided capital, utility, and chemical make-up costs for the $\mathrm{K}_{2} \mathrm{CO}_{3}$ scrubbing units. Flowsheets and equipment sizing were not provided because of the nonproprietary nature of our agreement. However, these could be made available if a contract including a secrecy agreement were negotiated.

The Glitsch Company supplied details for the design of a DEA regenerator tower and tower internals. This, when combined with the technique of William L. Bolles of the Monsanto Chemical Company for tray design in multipass towers, should provide a firm basis for design of the DEA treatment section. A letter was sent to Koch Engineering Company detailing the tower specifications, and they also have agreed to supply tower designs.

An additional subroutine was developed and inserted in the Phillips' Process Design Analysis (PDA) program to complete the DEA plant model. The subroutine was integrated with the PDA system and is presently being debugged.

(7) Co shift conversion: Design of the CO shift sections of both the Hydrocarbonization and Synthoil facilities is well underway based on data supplied by the Girdler Company and the use of the Girdler catalysts. The design is based on four parallel trains. Each train has three reactors in series, with inter-reactor cooling to permit maximum CO conversion.

(8) Solids-liquid separation: Two centrifuge vendors were contacted to establish a basis for the evaluation of centrifugation: The Bird Machine Company and the Pennwalt Corporation.

The Pennwalt Corporation (Sharples-Stokes Division) provided ORIL with all available data on the testing of Synthoil liquids in Sharples centrifuges. However, all the data are at temperatures of about $200^{\circ} \mathrm{F}$; and at the conditions expected to be required (about $500^{\circ} \mathrm{F}$ ), no data are available. 
Conceptual design of the solids-liquid separation plant for synthoil was completed. Equipment sizing and costing and utility requirements are currently being determined.

The Synthoil solids-liquid separation plant is much larger than for the Hydrocarbonization process, due to the higher throughput of liquid products. Because the product is more viscous, Synthoil also requires a higher operating temperature for filtration or centrifugation ( 450 to $550^{\circ} \mathrm{F}$ vs $350^{\circ} \mathrm{F}$ in the Hydrocarbonization process). Hence, diatomaceous earth is required for precoating filters since coal cannot be used at temperatures much over $500^{\circ} \mathrm{F}$ because of melting. To reduce the cost of the separation plant, centrifugation was considered. Although it is not clear yet whether centrifugation alone can perform the separation satisfactorily, the use of centrifuges as a thickening step does appear both feasible and economically desirable. The partially clarified overflow from centrifugation would be recycled to the coal slurrying section. The savings in purchased equipment cost alone, considering the use of centrifuges followed by filters vs only filters, is over $\$ 50$ million ( $\$ 24$ million vs $\$ 77$ million). Diatomaceous earth costs are reduced from about $\$ 11,000$ per day to about $\$ 2,300$ per day. Hence, filtration alone will not be considered as an alternative. The alternatives now under evaluation are centrifugation alone or centrifugation followed by filtration.

The Johns-Manville Company provided a conceptual design of a rotary drum precoat filter specifically designed for coal-derived liquids. This design was prepared under a contract with EPRI. Stearns-Roger provided the expertise in equipment design for the report. Although the filter design was not for the size expected to be needed in a commercial facility, it does give many of the filtration parameters required for such a design.

The Envirotech Corporation (Goslin Division) was visited to acquire background on their experience in the area of coal liquids separation problems. Information on the design, modifications, and operations of Goslin-Birmingham filters in the coal liquids area was obtained, and is currently being evaluated. 


\subsection{Hydrocarbonization Process}

J. M. Holmes, D. A. Dyslin, J. R. Johnson, D. S. Joy,

G. R. Peterson, and C. B. Smith

Preparation of the overall block flow diagram was completed, and flowsheet data were firmed based upon estimated yields from U.S. Steel's "Clean Coke" process. Material balances for various units are under preparation, and equipment sizing and cost estimating are underway. Recent experimental information from U.S. Steel indicated that a significant fraction of the light hydrocarbons in the recycle gas stream would be coked in the fluid-bed combustion unit if the gas were heated to $1750^{\circ} \mathrm{F}$. Therefore, the maximum gas temperature leaving the fluid-bed combustion unit was reduced to $1450^{\circ} \mathrm{F}$ and a char burner was added to make up the additional heat required for the Stage II hydrocarbonizer. In addition, a small percentage of steam will be added to the recycle gas to prevent coking of the tubes in the fluid-bed combustion unit.

Iinde Division of Union Carbide Corporation has prepared a design and cost estimate for a cryogenic system to separate the hydrocarbonizer make gases into a pipeline gas and a hydrogen stream. Hydrocarbon Research, Incorporated, agreed to provide the design and cost estimate for an H-oil hydrotreater for the tars and liquids produced by the hydrocarbonizers. The Ralph M. Parsons Company is preparing a design and cost estimate for the sulfur recovery unit in the hydrocarbonization plant.

During the current evaluation studies, consideration has been given to the selection of either a hydrocarbonization or a Synthoil system for evaluation as a scaled-down demonstration plant. Based upon interim results, a hydrocarbonization system will be recommended for this demonstration plant.

Work on the various sections of the hydrocarbonization flowsheet progressed as follows:

(1) Coal beneficiation: Under a subcontract, the McNally-Pittsburg Manufacturing Company has completed the process flowsheets, material balances, equipment tests, utility requirements, and is finishing up 
on the process description and capital cost estimates for the coal yard and coal beneficiation plant for the hydrocarbonization facility.

Truck and train coal unloading equipment is provided in the coal yard in conjunction with rotary breakers for reducing the run-of-mine (ROM) coal to 2 in. $x 0$ size. A line storage of 800,000 tons of coal is provided in three sets of parallel rows with coal stacker-reclaimers. The line storage ensures continuous operation of the beneficiation plant, and the design of the line storage provides, to some extent, blending of the sized coal.

In the beneficiation plant, the coal is screened ( \pm 28 mesh) into a coarse fraction ( 2 in. $\mathrm{x} 28 \mathrm{M}$ ) and a fine fraction ( $-28 \mathrm{M} \mathrm{x} 0$ ). The coarse coal fraction is processed @ $1.40 \mathrm{sp}$ gr in heary media cycloid separators. The washed or beneficiated coal is the float fraction from the cycloid separators. It is dewatered and crushed $-1 / 4$ in. $x O$ and is subsequently combined with the cleaned fine coal.

The sink fraction from the first-stage separation is processed in a second-stage system at a $1.85 \mathrm{sp} \mathrm{gr}$. The second-stage separation float fraction, being the major low-grade-coal stream, is also dewatered, crushed, and eventually combined with low-grade fine coal. The sink fraction from the second-stage separation contains $71.33 \%$ ash and $9.76 \%$ sulfur and will be discarded.

The cleaning of the fine coal is effected in a water cyclone classifier@ $@ 100$ mesh. The clean fraction $(28 \mathrm{M} \times 100 \mathrm{M})$ is dewatered and combined with the clean coarse coal. The clean coal will contain 8.56 wt $\%$ ash, 2.2 wt $\%$ sulfur, and 11.5 wt \% surface moisture.

Present plans call for combining all low-grade fine coal ( $100 \mathrm{M} \times 0$ ) with the low-grade coarse fraction. The low-grade coal will contain 32.0 wt $\%$ ash, 3.78 wt $\%$ sulfur, and 13.9 wt \% surface moisture. The procedure of combining all the low-grade fines with the coarse fraction results in about $55 \mathrm{wt} \%-48 \mathrm{M}$ x O material in the low-grade coal. This high percentage of fines will cause considerable difficulty in the fluid bed combustor design and operation. Therefore, alternative processes are being studied to handle the low-grade coal fines. 
The total moisture contents of the high-grade and low-grade coal streams are 22.1 and 24.3 wt \% respectively.

These high moisture contents will introduce handling problems in the coal storage silos and high-pressure coal injection system. The surface moisture of the coal streams will be reduced by thermal drying to 2 and 5 wt $\%$ respectively.

Contacts were established with Petrocarb, Incorporated, and they have a.greed to provide preliminary flowsheets and a capital cost estimate for the high-pressure coal injection system to the coal oxidizer. The design entails transporting 1140 tons/hr of coal from atmospheric pressure to 120 psia.

Air Pollution Industries, Incorporated, has agreed to provide the design and a cost estimate for the venturi scrubbers for removal of particulate matter from the oxidizer exit gas stream prior to recompression. These scrubbers will be operated in series and handle about 100,000 cfm@120psia and 350\% F.

(2) Hydrocarbonization: The preliminary overall material balance calculations have been completed and updated to include all component information available January 5, 1976. Detailed mass balance calculations have been performed for the tar recovery quench tower and chiller and the purification system associated with the tar hydrotreater. The results of these detailed programs have been incorporated in the general. material balance program.

A start has been made in sizing the quench tower. It appears that three separate trains will be required, with each train handling the off-gas from two hydrocarbonizer reactors. The approximate dimensions of the quench towers are $38 \mathrm{ft}$ in diameter by $60 \mathrm{ft}$ high. The off-gas from the quench tower will have to be further cooled to $40^{\circ} \mathrm{F}$ to remove as much of the light oils as possible before being recycled to the fluid bed combustor. A portion of the oils will be cracked when heated to the temperatures required in the second-stage reactor. 
(3) Co shift conversion: The computer program for low-temperature CO shift provided by Girdler Chemicals was incorporated in the overall material balance program for the hydrocarbonization facility. A singlestage low-temperature shift reactor is sufficient to handle the Co levels expected in both the hydrocarbonizer and hydrotreater make gas streams.

(4) Acid gas removal: The Benfield Corporation was contacted to provide conceptual design and cost for two $\mathrm{CO}_{2}$ removal plants. The computer model for DFA treating described under Synthoil will be used for other acid gas removal plants.

(5) Fuel oil-solids separation: The Unit 19 conceptual design was completed. The estimated total plant capital cost is about $\$ 10$ million. Five rotary-drum filters are required, operating with sized coal as a precoat material. Equipment was listed and is currently being sized.

(6) Fluid-bed combustion: A preliminary design was developed for the fluidized-bed combustion system based on the 2550-MW( $t$ ) process heating requirements that existed at the end of the previous reporting period. This design consists of six modules, each module having 10 fluidized beds for generating 600-psi superheated steam and heating two streams of hydrocarbonizer recycle gas, one stream being heated to $1000^{\circ} \mathrm{F}$ and the second stream being heated to $1750^{\circ} \mathrm{F}$.

A design criteria document was prepared and negotiations entered into with Fluidized Bed Combustion Company (FBCC) for them to develop a design and cost estimate for the atmospheric fluidized-bed combustion system. The subcontract with FBCC is to cost $\$ 51,500$ based on preliminary negotiations.

Revised design criteria are being developed from improved definitions of the coal beneficiation process and the hydrocarbonization process. Less coal will be burned in the fluidized-bed combustion system so no electricity will be exported as was previously planned. The maximum temperature of the recycle gas will be reduced to $1450^{\circ} \mathrm{F}$ to prevent a coke residue buildup on the interior of the heat exchanger tubes. Also, a nitrogen-rich gas stream will be heated to $1000^{\circ} \mathrm{F}$ for pretreatment of the coal before feeding the coal to the hydrocarbonizer vessels. These revised design criteria will be incorporated in the design criteria document DC-XED-12275-1 before FBCC initiates their work. 
7. BIOMEDICAL AND ENVIRONMENTAL RESEARCH

C. W. Gehrs

Research activities continue in all funded areas. A feasibility study has shown the coupling of a lower tier testing system with chemical fractionation to be a valid system. Fabrication of the exposure chamber for gaseous effluent mixtures is nearing completion. Initial investigations into the fate and availability of a model PAH compound in water show that it has a high affinity to organic particulate matter. Both grazing (zooplankton) and benthic (mayfly nymphs) food chains are able to obtain and bioaccumulate the compound from the organic matter. Acquisition of Iiterature on the bioaccumulation and toxicity of trace elements released in aqueous effluents of coal conversion has been completed and a qualitative index of toxicity developed. Activities in gathering and disseminating published information are aiding the research scientists in several areas of the Program.

\subsection{Biology Division}

R. F. Kimball

J. L. Epler, Alice A. Hardigree, Jennifer A. Young, and T. Ho (Biology Division)

$$
\text { with }
$$

M. R. Guerin, I. B. Rubin, and C. H. Ho (Analytical Chemistry Division)

The initial work on a crude product from a coal conversion (liquefaction) process has been extended to subfractionation of the neutral components and the potential genetic hazards assayed with the Ames system. Parallel analytical work with liquid extraction procedures coupled with gas chromatography has given the preliminary evaluation of the constituents and shows correlation with known mutagens. Thus, as a feasibility study, the work with synthetic fuel processes has shown that the approach with lower tier testing along with chemical fractionation is valid. 
The applicability of genetic results in the lower tier system to higher organisms (and to carcinogenesis) is still in question. Thus we have begun the work to extend the testing of environmental effluents (mixtures) to higher organisms. Suspect fractions have been used in the human leukocyte system, yeast, and Drosophila. Comparative data will be available in the near future.

Work has begun on samples from the oil shale process and the gasification process.

\subsection{Environmental Sciences Division}

C. W. Gehrs

Transport and bioaccumulation of polycyclic aromatic hydrocarbons (PAH) in aquatic systems (S. E. Herbes)

Because of their carcinogenic potential, polycyclic aromatic hydrocarbons ( $\mathrm{PAH}$ ) have been identified by preliminary literature evaluations as compounds of particular environmental concern. Moreover, the extremely low water solubilities of many PAH suggest that bioaccumulation within food chains, which may culminate in exposure to humans, may occur. Both soluble and particulate PAH forms may occur in natural waters, and either or both may be accumulated by organisms. Initial research, therefore, has attempted to characterize partitioning of a model PAH compound between soluble and particulate forms, and to evaluate uptake, metabolism, and bioaccumulation rates of both soluble and particulate PAH by aquatic organisms.

The results suggest that anthracene would be present in significant amounts in both soluble and particulate phases at particulate loadings commonly encountered in natural waters (10-100 mg/liter). Further research utilizing other labeled PAH compounds will attempt to elucidate the relationship between physical characteristics of PAH compounds (e.g., water solubility or parachor) with partitioning behavior. A joint project with the Analytical Chemistry Division will then attempt to confirm laboratory results with gas chromatographic analysis of PAH partitioning behavior in wastewater and natural waters. 
A. Partitioning of PAH between soluble and particulate forms. Because the routes of environmental transport and fate of PAH compounds may be dependent largely upon the initial compound form, an understanding of the partitioning of $\mathrm{PAH}$ between soluble and particulate phases is essential. In initial studies $9-{ }^{14} \mathrm{C}$-anthracene has been utilized as a model $\mathrm{PAH}$ compound because, while not carcinogenic, its solubility does not differ greatly from those of more hazardous PAH, such as 3,4-benzpyrene and 1,2,5,6-dibenzanthracene. Autoclaved yeast cells, which have been used to simulate suspended organic matter in natural waters, were incubated with continuous shaking with low levels of ${ }^{14} \mathrm{C}$-anthracene (usually about $4000 \mathrm{dpm}$ ) and appropriate concentrations of unlabeled carrier in $50 \mathrm{ml}$ of membrane-filtered spring water. After $2 \mathrm{hr}$, flask contents were centrifuged and each phase was extracted three times with hexane (which removed $98 \%$ of the ${ }^{14} \mathrm{C}$-anthracene). Extracts were then combined and anthracene content determined by liquid scintillation counting.

Results indicated that the partitioning coefficient was a constant (i.e., a constant fraction of anthracene was adsorbed) over four orders of magnitude of anthracene concentrations (up to $40 \%$ saturation in the water). From the temperature dependence of the partition coefficient the heat of adsorption was determined to be $5.2 \mathrm{kcal} / \mathrm{mole}$, a value characteristic of physical adsorption. The effect of the suspended solids concentration was pronounced (Fig. 7.1): anthracene adsorption decreased rapidly as the equilibrium water concentration decreased. The fraction of anthracene adsorbed by yeast cells was an order of magnitude greater than the fraction adsorbed by similar concentrations of suspended clay particles.

\section{B. Uptake of anthracene by Daphnia magna. Because zooplankters} form the initial link of many aquatic food chains, rates of uptake and metabolism of $\mathrm{PAH}$ by zooplankton may determine largely the extent of bioaccumulation of $\mathrm{PAH}$ throughout aquatic ecosystems. Uptake of ${ }^{14} \mathrm{C}-$ anthracene by Daphnia magna, a common zooplankter in natural waters, has thus been investigated.

Cultures of 2- to 3-day-old Daphnia were incubated with $9-{ }^{14} \mathrm{C}$-anthracene in membrane-filtered spring water with or without an autoclaved particulate food source added. Samples of 20 organisms were removed after intervals, 


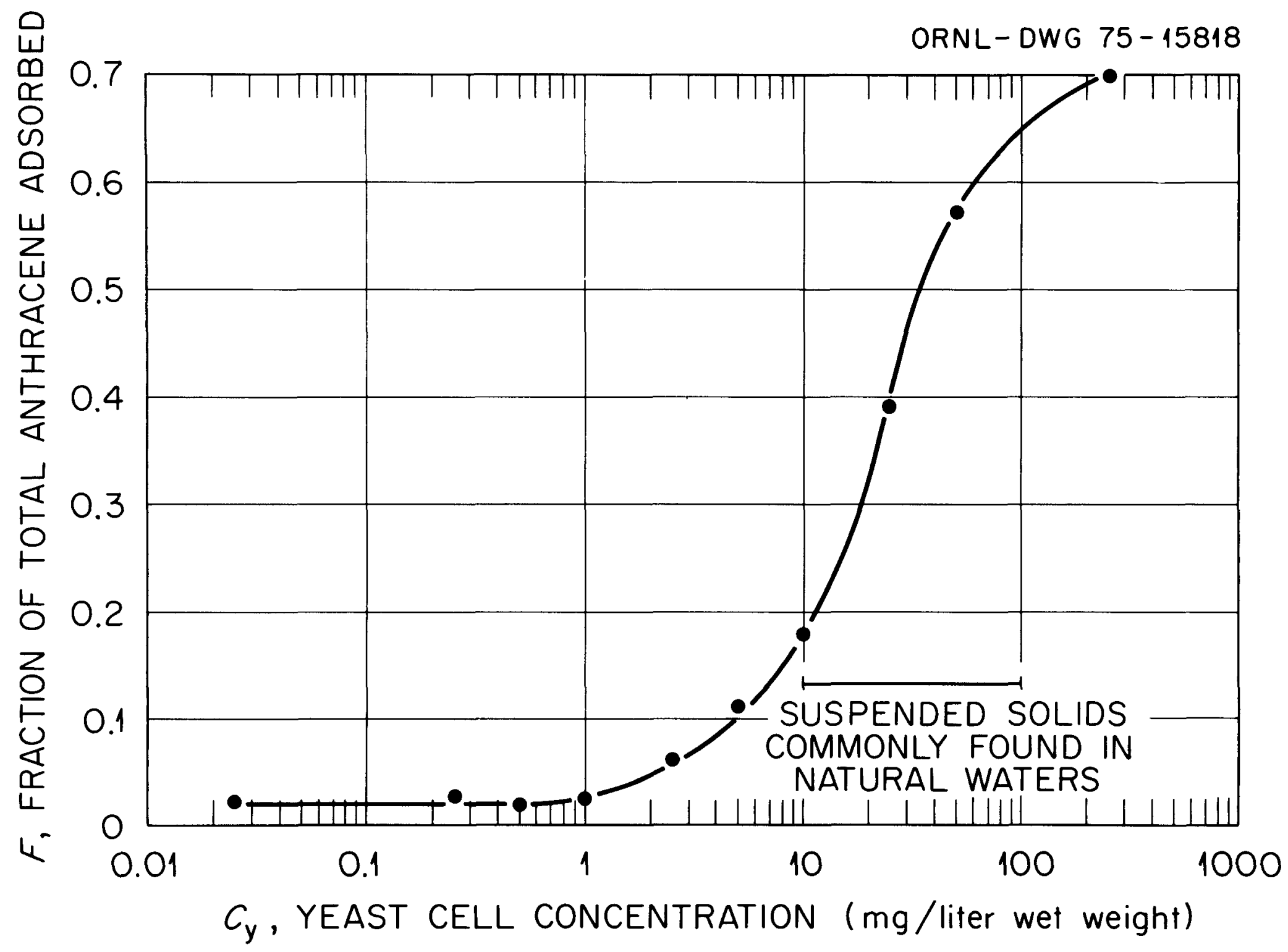

Fig. 7.1. Adsorption of $9-{ }^{14} \mathrm{C}$-anthracene by autoclaved yeast cells. Anthracene concentration $\simeq 0.02 \mu \mathrm{g} / l @ 24.0 \pm 0.5^{\circ} \mathrm{C}$. 
and labeled anthracene was extracted by grinding in acetone and measured by liquid scintillation. Anthracene partitioning was determined by centrifugation of water samples and extraction of both phases with hexane. Water-soluble metabolites were quantitated by extraction of water samples with ethyl acetate, rotary evaporation, and separation of the residue on thin-layer chromatographic plates. Developed chromatograms were than scraped, extracted, and radioactivity determined by liquid scintillation.

Daphnia were observed to take up anthracene rapidly, reaching a maximal level within $60 \mathrm{~min}$, and then declining slowly over a period of days. Extent of uptake from particulate material exceeded that from the soluble phase by about two-fold. Excretion of one or possibly two watersoluble metabolites coincided with the decrease in the fraction of anthracene present within the organisms (Fig. 7.2). Release of radioactivity from the Daphnia when transferred to unlabeled water followed sequential first-order kinetics with rate constants of 0.53 and $0.12 \mathrm{hr}^{-1}$ respectively; the rate constants correspond nearly identically to observed rates of gut elimination and anthracene metabolite formation. Bioaccumulation at equilibrium was calculated to be approximately 200-fold.

C. Uptake of anthracene by Hexagenia (mayfly) nymphs. The potential presence of significant quantities of $\mathrm{PAH}$ adsorbed onto particulate material in natural waters suggests that uptake by benthic organisms may be an important mechanism of PAH transport. Nymphs of Hexagenia sp. were utilized in initial experimentation because they constitute an important food source for many fish, thus enabling expansion to later bioaccumulation studies.

Hexagenia nymphs were collected from the sediment of Watts Bar Lake and were maintained in laboratory aquaria. Organisms were incubated individually with $50 \mathrm{ml}$ spring water containing labeled anthracene; autoclaved yeast cells were added in duplicate experiments to determine uptake kinetics from particulate material. Organisms, water, and centrifuged particulate material were extracted and ${ }^{14} \mathrm{C}$-anthracene determined by liquid scintillation.

Although nymphs varied widely in size, initial experimentation demonstrated a direct relationship between organism mass and amount of label 


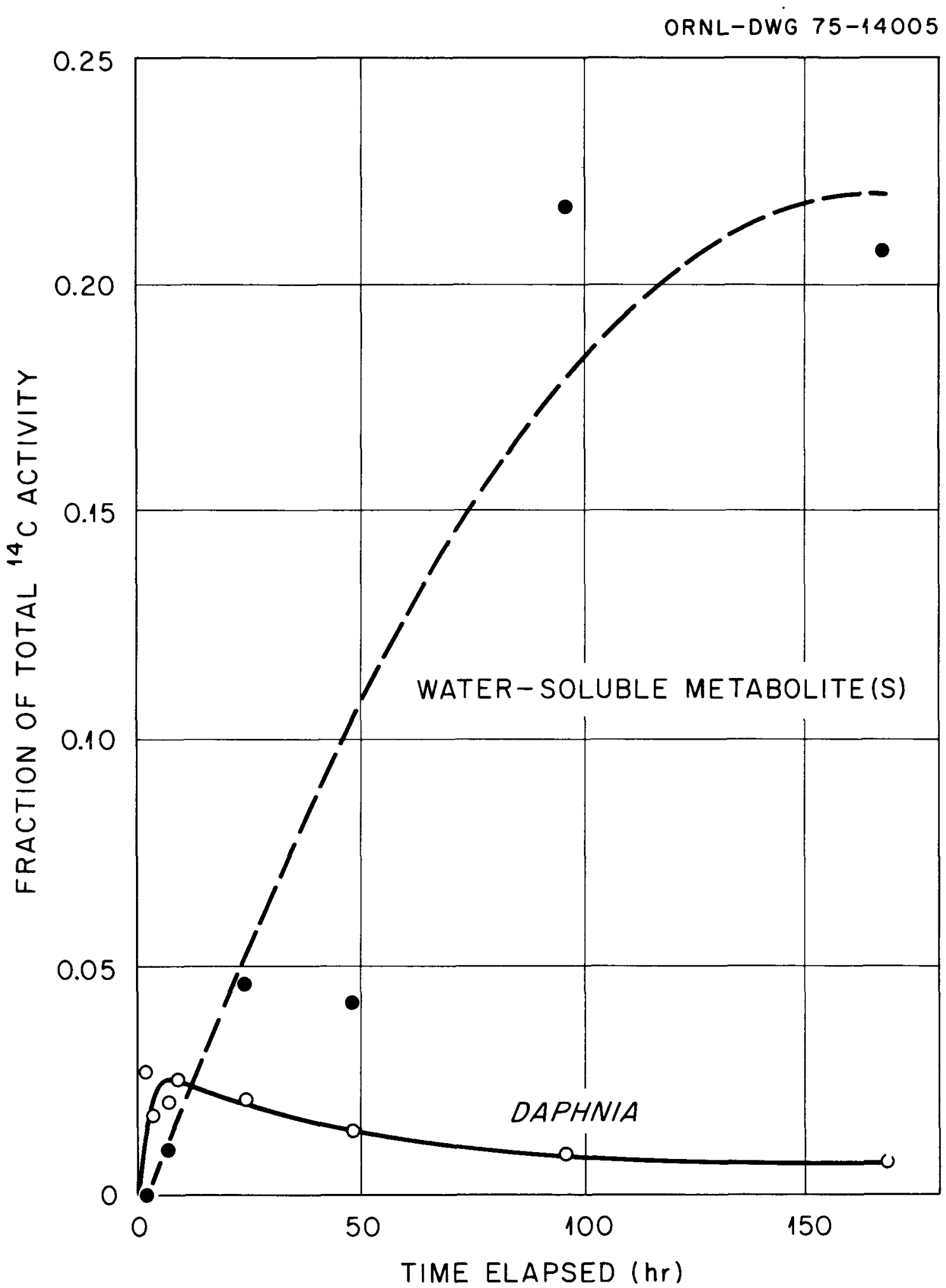

Fig. 7.2. Uptake and metabolism of $9-{ }^{14} \mathrm{C}$-anthracene by Daphnia magna fractions of total activity in organisms (one Daphnia/ $20 \mathrm{ml}$ ) and in form of water-soluble metabolic products. Remainder of ${ }^{14} \mathrm{C}$ present as anthracene in solution and adsorbed onto suspended particulate matter. Initial anthracene concentration $\simeq 0.02 \mu \mathrm{g} / \ell @ 24^{\circ} \mathrm{C}$. 
accumulated after a specified time; gross counts were therefore normalized after weighing nymphs. Results (Fig. 7.3) resembled those from the Daphnia uptake studies, although no decrease in ${ }^{14} \mathrm{C}$ within nymphs due to metabolism was observed. Rapid initial first-order uptake occurred with or without the presence of suspended yeast cells. A much slower (although continuous) uptake corresponded to a first-order decrease in the fraction of anthracene bound to particulate material in suspension. Apparently uptake from soluble phase is 40 times more rapid than that from particulate phase, while total bioaccumulation with particulate material present (3500-fold within $28 \mathrm{hr}$ ) is nearly double that from the soluble phase alone.

The results of uptake experiments with both Daphnia and Hexagenia underscore the importance of the initial form of $\mathrm{PAH}$ in determining rates and extent of bioenvironmental transformation and accumulation. Future research will be directed toward elucidation of PAH bioaccumulation through higher trophic levels in aquatic ecosystems.

Biogeochemical cycling of trace elements from coal conversion in aquatic ecosystems (B. G. Blaylock, S. G. Hildebrand, R. M. Cushman)

The literature review on toxicity and bioaccumulation of trace elements in coal conversion aqueous effluents is proceeding on schedule; the acquisition of literature is complete. A qualitative index of toxicity for those elements initially selected for investigation has been developed (Table $7.1)$.

Assessment of effects of gaseous effluent mixtures on terrestrial plants (D. Shriner and S. McLaughlin)

Fabrication of the exposure chamber control and monitoring systems to be used for acute and chronic toxicity studies is nearing completion. The exposure chamber has been constructed and will be used initially by the Bio/Organic Analysis group of the Analytical Chemistry Division as they assist in the development of methodology for the generation and dilution of certain of the organic compounds to be tested.

Renovation of laboratory space for the exposure unit adjacent to greenhouse facilities is continuing. 

Table 7.1. Preliminary indication of the extent of available information on toxicity to aquatic biota of trace elements in coal a

Trace elements in coal

\begin{tabular}{|c|c|c|c|c|c|}
\hline $\mathrm{Ag}$ & 1 & $\mathrm{Hf}$ & 0 & ${ }^{*} \mathrm{Se}$ & 1 \\
\hline *Al & 1 & $\mathrm{Hg}$ & 2 & ${ }^{*} S i$ & 1 \\
\hline *As & 2 & In & 0 & $\mathrm{Sm}$ & 0 \\
\hline $\mathrm{Au}$ & 1 & $\operatorname{Ir}$ & 0 & ${ }^{*} \mathrm{Sn}$ & $I$ \\
\hline$* B$ & 1 & *Ia & 1 & ${ }^{*} \mathrm{~S} r$ & 1 \\
\hline $\mathrm{Ba}$ & 2 & Li & 1 & *Ta & 0 \\
\hline $\mathrm{Be}$ & 1 & Lu. & 0 & $\mathrm{~Tb}$ & 0 \\
\hline$* B i$ & 0 & $* \mathrm{Mg}$ & 2 & ${ }^{*} \mathrm{Te}$ & 0 \\
\hline$* \mathrm{Br}$ & 1 & *Mn & 2 & *Th & $I$ \\
\hline${ }^{*} \mathrm{Cd}$ & 2 & *Mo & 1 & *Ti & 1 \\
\hline $\mathrm{Ce}$ & 1 & $* \mathrm{Nb}$ & 0 & $* T 1$ & 1 \\
\hline$* \mathrm{Co}$ & 2 & *Na & 0 & $* U$ & 1 \\
\hline${ }^{*} \mathrm{Cr}$ & 3 & $* N i$ & 2 & $* V$ & 1 \\
\hline${ }^{*} \mathrm{Cs}$ & 0 & $* \mathrm{~Pb}$ & 2 & ${ }^{*} W$ & 1 \\
\hline${ }^{*} \mathrm{Cu}$ & 3 & Po & 0 & $* Y$ & 0 \\
\hline Dy & 0 & ${ }^{*} \operatorname{Pr}$ & 0 & $\mathrm{Yb}$ & 0 \\
\hline$E u$ & 0 & $\mathrm{Ra}$ & 0 & $* \mathrm{Zn}$ & 3 \\
\hline$* \mathrm{Fe}$ & 2 & $* \mathrm{Rb}$ & 1 & $* Z \mathrm{Zr}$ & 1 \\
\hline$*_{\mathrm{Ga}}$ & 0 & ${ }^{*} \mathrm{Sb}$ & $I$ & & \\
\hline${ }^{*} \mathrm{Ge}$ & 0 & *SC & 0 & & \\
\hline
\end{tabular}

$a_{O}=$ no information reviewed to date.

$I$ = limited data.

2 = moderately studied.

3 = well studied.

* = measured in COED aqueous effluents to date. 
In advance of the collection of effluent gases from the bench-scale hydrocarbonization plant at ORNI, acute toxicity studies will be carried out using a synthetic mixture of gases representative of classes of potentially phytotoxic compounds expected in the plant effluent.

The preliminary synthetic effluent will consist of a mixture of the following compounds in gaseous phase: ethylene, hydrogen sulfide, phenol, methane, carbon monoxide, xylene, and monomethylamine.

The acute toxicity studies will be conducted using the compounds of this synthetic mixture singly and in combination to determine visible and physiological responses of exposed Phaseolus vulgaris (kidney bean) test plants.

\subsection{Information Division Emily Copenhaver}

Subject specialists from the Ecological and Environmental Sciences Section of the Information Center Complex continue to work on the broad literature overview on coal conversion effluents, and the background material gathered thus far is located in the Resource Center in Bldg. 2028 or with the subject specialists. It has been used by several members of the Ecological Science Division during this quarter, and is taking shape as a sizeable hard copy collection.

The Environmental Response Center has provided information services to Steve Hildebrand and associates of the Ecological Science Division in a related study of the role of trace elements emitted from coal conversion activities in environmental cycling (primarily in biota).

The Environmental Mutagenic Information Center is continuing its efforts in identifying compounds that are products of coal conversion processes and matching these compounds against their mutagenicity file. The resultant information is relayed to $R$. F. Kimball and associates in the Biology Division. In addition, FMIC is adding general group classification tags to all chemicals in their mutagenicity file to make it possible to access their files by general class designations such as "polyaromatic hydrocarbons." This is particularly important for the coal conversion work in that often only the general class of compounds is known. 


$$
\begin{gathered}
\text { 7.4 Health Physics Division } \\
\text { J. K. Baird }
\end{gathered}
$$

R. B. Gammage

An assessment program has started aimed at evaluating instrumentation available, or needed, to cope with health protection problems arising from nonnuclear energy producing systems. Attention will focus on the occupational hazard associated with carcinogenic polycyclic hydrocarbons. Problem areas will be identified in energy production or usage where new techniques might make the most significant impact. 


\section{ENGGINEERING EVALUATIONS OF NUCLEAR PROCESS \\ HEAT FOR COAL CONVERSION}

W. R. Gambil工

$\underline{\text { Summary }}$

Preliminary results for a plant designed to steam gasify coal directly with VHTR heat are given. Design studies by United Engineers and Constructors on two H-coal plants (all-coal and VHIR-driven) are described, as is an evaluation of pollution and water consumption related to selected coal conversion processes. Two new program proposals were transmitted to ERDA-Fossil Energy and the materials evaluation effort reviewed.

After assembling available data on steam gasification rates (percent carbon per minute) vs temperature for various coal types, a preliminary flowsheet was prepared for a VHTR-driven steam-coal gasification process. The net endothermic heats of reaction given in the West German literature for dry hard coal (1.4 Gcal/tonne, or $2520 \mathrm{Btu} / \mathrm{lb}$ ) and for dry lignite ( 1.1 Gcal/tonne, or $1980 \mathrm{Btu} / \mathrm{Ib}$ ) appeared to be $13 \%$ lower than standard values for the steam-carbon reaction. Examination, however, showed these values to be approximately correct since they reflect the percent carbon in the coal, the reaction temperature considered, and simultaneous mildly exothermic reactions. With a $3000-\mathrm{MW}(t)$ VHTR $\left(1800^{\circ} \mathrm{F}\right.$ core-exit He temperature), 7169 tons per day (TPD) of coal would be converted to 6186 TPD of clean syngas with a molar ratio of $\mathrm{H}_{2}$ to $\mathrm{CO}$ of 2.95 and to 431 TPD of methane. The fluid-bed temperature is $1472^{\circ} \mathrm{F}$ and the overall plant thermal efficiency $\sim 75 \%$. Of the 3000 thermal MW, $997 \mathrm{MW}(t)$ would be available outside the process, producing, e.g., $319 \mathrm{MW}(\mathrm{e})$ for a $32 \%$ net power generation efficiency.

Assuming the availability of an external $\mathrm{H}_{2}$ supply, an estimate of the flows in an H-coal plant producing syncrude was made. If driven by a 3000-MW(t) VHIR, a thermochemical $\mathrm{H}_{2}$ unit would produce (for a $47 \%$ efficiency) 932 TPD of $\mathrm{H}_{2}$ and 7453 TPD of $\mathrm{O}_{2}$, consuming 1398 gpm of $\mathrm{H}_{2} \mathrm{O}$. Using as a basis a net yield of $\mathrm{C}_{4+}$ liquid of $2.3 \mathrm{bbl} / \mathrm{ton}$ of dry coal, a 
coal heating value of $20 \times 10^{6}$ Btu/ton, a $\mathrm{H}_{2}$ consumption of $7080 \mathrm{scf} / \mathrm{bbl}$ of $\mathrm{C}_{4+}$ liquid, and all $\mathrm{H}_{2}$ produced used in the process, the net effect would be to increase the syncrude yield by 54\%. Essentially all the $\mathrm{O}_{2}$ would be available for export since process use is negligible. No coal would be used to make $\mathrm{H}_{2}$ ( $\sim 35 \%$ of the total coal feed normally would be required for this case), but the cost of $\mathrm{H}_{2}$ from water will probably be about triple that from coal. In addition, the overall energy conversion efficiency would decrease from $66.3 \%$ to $54.6 \%$, a decrement of about twelve percentage points. Using a higher, and more probable, $\mathrm{H}_{2}$ consumption of $8000 \mathrm{scf} / \mathrm{bbl}$ of $\mathrm{C}_{4+}$ liquid (18,400 scf $\mathrm{H}_{2} /$ ton of dry coal) to produce a light syncrude, the results are the same with the exception that the energy conversion efficiency would decline from $63.4 \%$ to $41.6 \%$, a decrement of about twenty-two percentage points. The comparison clearly indicates that a heavy fuel oil product, requiring $\sim 4000 \mathrm{scf} \mathrm{H}_{2} / \mathrm{bbl}$, would be relatively more attractive for the external $\mathrm{H}_{2}$ supply case. In any event, $\mathrm{H}_{2}$ from water will not be competitive with $\mathrm{H}_{2}$ from coal until coal prices increase to much higher levels.

We met with representatives of United Engineers and Constructors (UE\&C), Philadelphia, on November 20 and on December 23 to review the status of two subcontract studies, titled "Evaluation of a Coal Iiquefaction Process Using Either a Nuclear or Fossil Heat Source" and "An Evaluation of Pollution and Water Consumption Related to Selected Coal Conversion Processes," each of which will be reported in final form in January 1976. The first study is of the H-coal process using either a combustion- or a convectively-heated reformer section.

Design data were taken from Hydrocarbon Research, Incorporated, reports, the independent Amoco review, the 1973 NPC evaluation, and the 1974-1975 DCCU Annual Report. The all-coal plant will produce 1164,000 barrels per day (BPD) from a coal feed rate of 60,000 TPD. The coal feed rate will be the same for the VHIR-driven plant, with a net increase in liquids production of $13.4 \%$ (186,000 BPD). There will probably be nine processing lines beyond the coal storage area. The coal selected is a western Kentucky high volatile b bituminous coal with a higher heating value of $12,080 \mathrm{Btu} / \mathrm{Ib}$ and containing 7.5 wt $\%$ water, 9.5 wt $\%$ ash, 
and 3.5 wt $\%$ sulfur. An air-blown fluid-bed coker is used to crack the residual oil $\left(975+{ }^{\circ} \mathrm{F}\right)$ to a high heating value, 4.3 wt $\%$ sulfur coke. The chemical reactors operate at $780^{\circ} \mathrm{F}, 2700 \mathrm{psig}$, and a space velocity of $28 \mathrm{lb} \mathrm{coal} / \mathrm{hr} \mathrm{ft}^{3}$. The total $\mathrm{H}_{2}$ consumption is $\sim 0.052$ ton $\mathrm{H}_{2} /$ ton coal, or $18,500 \mathrm{scf} \mathrm{H}_{2} /$ ton coal. The reformer is fired with $\mathrm{C}_{1}-\mathrm{C}_{6}$ gas and operates at an exit condition of $1400^{\circ} \mathrm{F}$ and 350 psig. By-products will be coke, liquid $\mathrm{NH}_{3}$, and sulfur. The nuclear variant will include a 3000-MW(t) VHTR, an intermediate heat-exchange 100p, and a reformer convectively heated by $\mathrm{He}$ which enters at a temperature of $1500^{\circ} \mathrm{F}$. The larger plant UE\&C is evaluating will require more than the $131 \mathrm{MW}(\mathrm{e})$ generated and used in-plant in the General Atomics/Stone and Webster (GA/S\&W) reference design for coal to SPG. We agreed that the VHTR plant would be based on power from the VHTR and the all-coal plant on power from a coal-fired power plant, using a $38 \%$ net conversion efficiency in each case.

At this time, the study shows somewhat higher production costs for the plant with a He-heated reformer, though the heating value of the net crude-liquid and gas production is $17.6 \%$ higher than for the all-coal plant. In each case, the overall energy conversion efficiency is approximately 65\%. The UE\&C work seems to include sufficient detail to evaluate more realistically the relative promise of the crude liquids VHTR case identified in their June 1975 overview report.

The goal of the second study is to identify, quantify, and compare the pollution outputs $\left(\mathrm{SO}_{2}, \mathrm{NO}_{\mathrm{x}}\right.$, particulates, and solid waste) and water usages of the GA/S\&W, H-coal, Hygas, Koppers-Totzek, and Lurgi processes. Very little information has been located on coal-conversion plant solidwaste leaching rates. Briefly, this study shows that plants utilizing nuclear process heat are characterized by projected $\mathrm{SO}_{\mathrm{X}}$ and $\mathrm{NO}_{\mathrm{X}}$ emissions approximately 5 to 30 fold smaller than equivalent fossil plants, but that the pollutant outputs of the nonnuclear plants would be well below EPA power plant standards.

In addition to the above, we have requested UE\&C to review and revise their report to ORNL of June 30, 1975 ("Engineering Evaluation of Process 
Heat Applications for Very High Temperature Nuclear Reactors") with regard to four areas: relative process efficiencies, gas delivery pressure, hydrogen purities, and methanol production with syngas from the GA/S\&W process.

Two revised program and budget proposals, one covering the period January 1976 through September 1976 and the other the interval January 1976 through september 1977, were prepared, reviewed, and formally transmitted to ERDA-Fossil Energy.

The materials evaluation program for three processes (steam/coal gasification, steam/ $\mathrm{CH}_{4}$ reforming, and thermochemical $\mathrm{H}_{2}$ production) was reviewed with Metals and Ceramics Division personnel.

The Institute of Gas Technology's final report on hydrogen was received and partially reviewed. The report (three volumes) is titled "Survey of Hydrogen Production and Utilization Methods" and addresses the following topics: potential demands; production by electrolysis, from coal, via thermochemical cycles, and by photosynthetic and other processes; current commercial generation technology (reforming and partial oxidation); transmission, storage, and distribution; industrial and residential utilization; and $R \& D$ recommendations. 


\author{
ORNL -5120 \\ UC-90d - Coal Conversion and \\ Utilization - Liquefaction
}

\title{
INTERNAL DISTRIBUTION
}

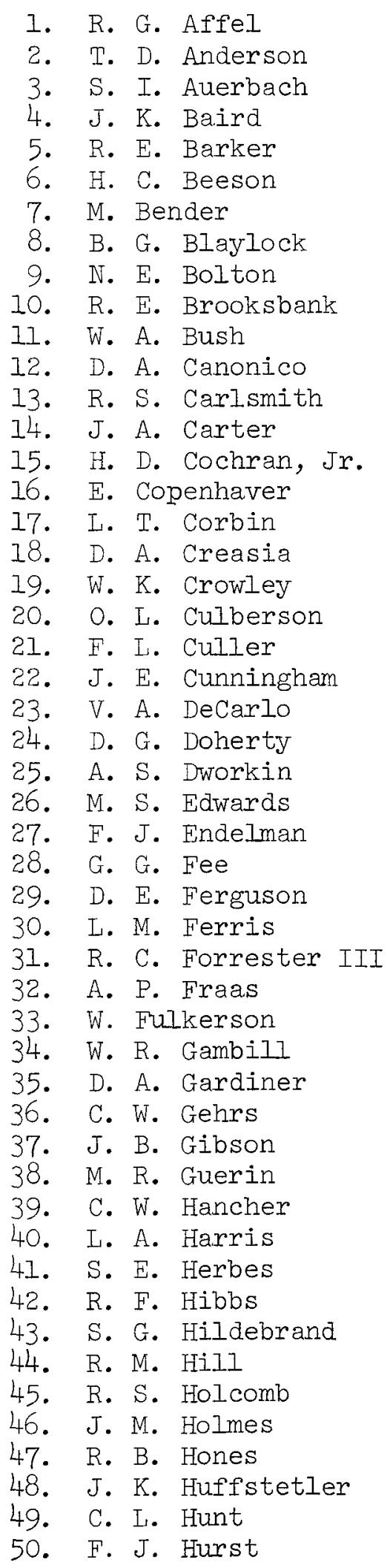

51. G. R. Jasny, Y-12

52. W. F. Johnson

53. I. L. Johnston

54. R. I. Jolley

55. J. E. Jones

56. D. S. Joy

57. S. Ka.tz

58. O. I. Keller

59. R. F. Kimball

60. J. J. Kurtz

61. W. R. Laing

62. P. M. Lantz

63. R. S. Livingston

64. A. P. Malinauskas

65. G. B. Marrow, $Y-12$

66. W. R. Martin

67. W. J. McDowell

68. C. J. McHargue

69. J. R. McWherter

70-72. W. R. Mixon

73. J. E. Mrochek

74. G. E. Moore

75. P. Nettesheim

76-85. J. P. Nichols

86. I. C. Oakes

87. G. R. Peterson

88-89. T. W. PickeI

90. W. W. Pitt

91. H. Postma

92. J. J. Prislinger

93. W. T. Rainey

94. D. E. Reichle

95. C. R. Richmond

96. B. R. Rodgers

97-98. M. W. Rosenthal

99. W. I. Russell

100. Royes Salmon

1O1. R. W. Schede, Y-12

102. C. D. Scott

103. A. J. Shor

104. D. S. Shriner

105. W. D. Shults

106. C. B. Smith

107. G. P. Smith

108. I. Spiewak

109. R. I. Spore

110. E. G. St. Claix

111. J. B. Storer

112. R. A. Strehlow

113. O. K. Tallent 
114. E. H. Taylor

115. A. J. Thompson

116. D. B. Trauger

117. W. C. Ulrich

118. P. R. Vanstrum, $Y-12$

119. J. S. Watson

120. J. R. Weir

I2I. P. R. Westmoreland

122. M. E. Whatley

123. J. C. White
124. M. K. Wilkinson

125. L. V. Wilson

126. R. G. Wymer

127. G. L. Yoder

128. C. S. Yust

129. Patent office

130-134. Lab. Records

135. Lab. Records-RC

136-138. Central Research Library

139. Document Reference Section

EXTERNAL DISTRIBUTION

ERDA, Oak Ridge Operations

140. Research and Technical Support Division

ERDA, Washington

141. D. Ballantine, DBER

142. J. D. Batchelor, FE
143. T. Beresovski, DRRD

154. G. A. Mills, FE

155. W. E. Mott, DBER

144. E. I. Clark, FE

156. M. B. Neuworth, FE

145. N. P. Cochran, FE

157. E. S. Pierce, DPR

146. C. W. Edington, DBER

158. H. E. Podall, FE

147. R. Franklin, DBER

159. J. I. Powell, FE

148. W. S. Harmon, FE

160. Robert Rabin, DBER

149. G. E. Larson, FE

161. E. Schmetz, FE

150. T. K. Lau, FE

151. R. W. A. LeGassie, AA/PA

152. J. I. Liverman, AA/ES

162. G. Stapleton, DBER

163. R. E. Vener, FE

164. H. Wasson, DBER

153.

C. Miller, $\mathrm{FE}$

165. P. C. White, AA/FE

Department of Housing and Urban Development, 451 th Street, S.W., Washington, D. C. 20410

166. G. S. Leighton

167. J. H. Rothenberg

National Science Foundation, 1800 G Street, N.W., Washington, D.C. 20550 168. R. S. Goor

169. Charles Johnson

Resource Planning Associates, Inc., 44 Brattle St., Cambridge, Mass. 02138 170. Robert Rea

U.S. Environmental Protection Agency, ETRL, 1055 Laidlaw,

Cincinnati, Ohio 45237

171. William E. Pepelko

U.S. Environmental Protection Agency, Research Triangle Park, N.C. 27711

172. Charles B. Sedman

U.S. Steel Corp. Applied Research Laboratory, 125 Jamison Lane, Monroeville, Pa. 15146

173. N. S. Boodman, Section Supervisor 
University of Kentucky, Institute for Mining and Materials Research,

213 Bradley Hall, Lexington, Kentucky 40506

174. Theresa Wiley, Institute Librarian

175. O. J. Haun

176. J. K. Shou

177. Jet Propulsion Laboratory, Attn: Library Acquisitions, 4800 Oak Grove Drive, Pasadena, California 91103

178. Tom K. Brotherton, Vice President, Coalcon Company, Union Carbide Corp., P.0. Box 8361, South Charleston, West Virginia 25303

179. D. E. Eissenberg, Union Carbide Corp., 270 Park Ave., New York, N.Y. 10017

180. R. E. Davis, Kerr-McGee Technical Center, P.0. Box 25861, Oklahoma City, Oklahoma 73125

181. H. Beuther, GuIf Research and Development Company, P.O. Drawer 2038, Pittsburgh, Pa. 15230

182. Robert Hangebrauck, National Environmental Research Center, Research Triangle Park, North Carolina 27711

183. John W. Larson, Department of Chemistry, University of Tennessee, Knoxville, Tenn. 37916

184. William A. Peters, Massachusetts Institute of Technology, Department of Chemical Engineering, Cambridge, Mass. 02139

185. Donald Hanson, University of California, Department of Chemical Engineering, Berkeley, California 94720

186. S. G. Wellborn, Manager, Feedstocks Development, E. I. du Pont de Nemours \& Company, Inc., Wilmington, Delaware 19898

187-188. Jack Gillespie, UCCND, P. O. Box 1410, Paducah, Ky. 42001

189-193. The Director, Morgantown Energy Research Center, P.0. Box 800, Morgantown, West Virginia 26506

194-195. ERDA Pittsburgh Energy Research Center, U.S. Energy Research and Development Administration, Attn: Director for J. P. Barreca, 4800 Forbes Ave., Pittsburgh, Pa. 15213

196-418. Given distribution as shown in TID-4500 under UC-90d, Coal Conversion and Utilization - Liquefaction Category (25 copies - NTIS) 